\title{
„Wedelträger zur Rechten des Königs“ _ Am Beispiel von Lebensläufen hoher Beamten in der 18. Dynastie
}

\section{Dr. Sahar samir El-Badrawy}

Abstract:

Dieser Artikel mit dem Titel „Wedelträger zur Rechten des Königs" - Am Beispiel von Lebensläufen hoher Beamten in der 18. Dynastie handelt sich um eine Untersuchung zur Eigenschaften dieses Ehrentitels. Welche Sozialklasse und welche Ämter waren verlangt um diesen Titel tragen zu dürfen. Waren besondere Leistungen und persönliche Eigenschaften verlangt? Wie waren die politische Stellung eines Titelträgers und seine Beziehung zum König? Waren diese wichtige Persönlichkeiten Beamten, die der Bürokratie angehörten, oder Höflinge? Der Artikel übernimmt eine vollständige Untersuchung zum Lebenslauf der Personen, die den Ehrentitel trugen. Haben „Wedelträger zur Rechten des Königs“ in den Darstellungen einen Wedel in ihre Hände getragen? Der Artikel redet auch über die religiöse Bedeutung des Wedels. Da in der 19. und 20. Dynastie die Vorraussetzungen dieses Ehrentitels sich ändern, so beschränkt sich diese Untersuchung auf die 18. Dynastie.

\section{Schlïsselwörter:}

- Wedelträger

- Fächer und Wedel

- Verwaltung

- Beamtentitel

- Rang

- Ehrentitel

\footnotetext{
- Lecturer of Egyptology in: Minia Universität Tourism \& Hotels Fakultät dr.saharbadrawy@gmail.com
} 
Inschriften aus den Gräbern von hohen Beamten sowie Szenen von festlichen und militärischen Aufzügen auf den Tempelwänden weisen auf eine wesentliche hochwertige Persönlichkeit, die als Mitglied der Königsgefolge erscheint und den Titel „Wedelträger zur Rechten des Königs“ trägt. Diese deutlich auftauchende Persönlichkeit spornt an die Verantwortungen, Karriere und Erfahrungen anhand einer engeren Untersuchung auszuprägen. Die ersten Fragestellungen dieser Untersuchung lautet: Handelt es sich um zivilesmilitärisches oder religiöses Amt? Welche Aufgaben, Tätigkeiten und Verantwortungen gehören zu diesem Titel? Gehört der Träger dieser Titel „Wedelträger zur Rechten des Königs“ zu den Königsgefolgen? Welche Persönlichkeiten dürften diesen Ehrentitel tragen und seit welcher Zeitepoche? Ist dieser Titel auf eine besondere Sozialschicht beschränkt?

Eine Statue aus grauem Granit des gealterten Amenophis, Sohn des Hapu, im Ägyptischen Museum Kairo ${ }^{1}$ weist auf den Titel „Wedelträger zur Rechten des Königs“. Die Statue stellt (Imn-htp s3 $\mathrm{Hpw}$ ) als lebenserfahrenen, gereiften Mann dar. ${ }^{2}$ Er sitzt in betende Haltung. Das wiedergegebene schmale Gesicht mit Falten um den unlächelnden Mund, schweren Augenlider und schlaffe Brustmuskulatur und kräftiger Leib beweisen das Alter des 80-jährigen Amenophis. Seine lange, wellige Perücke lässt die Ohren unbedeckt, die Aufmerksamkeit reflektiert (Taf. 1). Er trägt einen langen, geknoteten Schurz, die sein kräftiger veralterten Leib verhüllt. Seine Hände liegen in der Haltung eines Betenden ausgestreckt auf den Oberschenkeln. Die Statue stammt aus dem NR, 18. Dynastie, Regierungszeit des Königs Amenophis III., 1403-1365 v. Chr. Der lange Text, über seinem

\footnotetext{
1 Ägyptisches Museum Kairo, Erdgeschoss, Saal 12, JE 38368, CG 42127; Statue entdeckt bei Legrain, gefunden nördlich des 7. Pylons des Amuntempel von Karnak; HELCK 1975, in: $L \ddot{A}$ I, S. 219.

${ }_{2}^{2}$ M. SALEH/H. SOUROUZIAN, Offizieller Katalog: Die Hauptwerke im Ägyptischen Museum Kairo, Mainz 1986, Statue Nr. 149; G. LEGRAIN, ,,Statues et Statuettes des Rois et des Particuliers “, Catalogue Général (42001-42138), I, Caire 1906, p. 78-80, pl.76 (Nr. 42127).
} 
Schurz lässt uns seine Biographie mit seiner aufwachsenden Titelränge zu erkennen.

Aus den Inschriften der Biographie des Amenophis, Sohn des Hapu erkennt man seine Familie und Karriere. Er entstammte einer unbedeutenden Familie der Deltastadt Athribis ${ }^{3}$ im 10. unterägyptischen Gau, wie er selbst in seiner Inschriften immer wieder hervorhebt. Er erwähnt mit besonderer Freude in seiner biographischen Inschrift auf einer seiner Statuen aus dem Amuntempel in Karnak ${ }^{4}$, wie schön diese Stadt aufgrund seiner Bitten zum König, ausgeschmückt worden war. Sein Vater hieß $(H p w)$, irgendein Titel ist von ihm nicht bekannt. Man kann erschließen, daß dieser keinen Titel trug, der wert gewesen war. Seine Mutter führte den Namen (Jtw). Die Inschriften zu Amenophis, Sohn des Hapu, berichten über seine Karriere erst während der Regierungszeit des Amenophis III., während vor der Thronbesteigung des Amenophis III. keine Hinweise vorhanden sind. Die erst erwähnte Amtstelle, die ihm der König zugeteilt

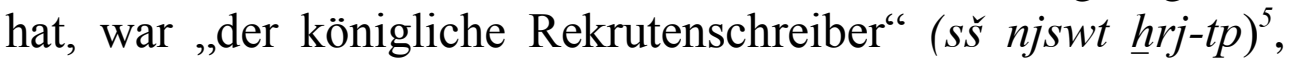
was uns hinweist, dass Amenophis, Sohn des Hapu, erst mit 50 Jahren in diese untergeordnete Beamtentstellung befördert worden war. Vielleicht hatte auch bei ihm eine Verbindung mit dem jungen König bestanden, der ihn nach seiner Thronbesteigung schnell die Beamtenlaufbahn durchlaufen ließ. Jedoch berichtet er nichts davon, ebenso geben die Inschriften keine Hinweise, was er vorher gewesen war. Seine Biographie erwähnt von der Zeit, in der er „Unterbeamter“ war, dass er während seiner Ausbildung die Stelle eines königlichen Schreibers bekam, nämlich: „Ich wurde zum (š́ njswt hrj-tp $)^{6}$

\footnotetext{
${ }^{3}$ Heute die Stadt Benha.

${ }^{4}$ L. BORCHARDT, Statuen und Statuetten von Königen und Privatleuten im Museum von Kairo, in: Catalogue Général, II, Berlin 1911-36, Statue Nr. 583 ; cols. 5ff.

${ }^{5}$ Diese Amtstelle (Rang) steht deutlich am Ende der neunte vertikale Zeile auf der langen Schürze der Statue Amenophis (CG 42127) aus Karnak; auch: L. BORCHARDT 1911-36, in: Cat. Gén., II, Statue Nr. 583, col.12.

6 „Königliche Schreiber als Unterbeamter“ (š̌ njswt hrj tp): In diesen Posten lernten sie die Verwaltung. Wahrscheinlich gehörte auch noch die Stellung eines „Soldatenschreibers“ ( $s \check{s}$
} 
befördert und wurde mit dem Gottesbuch bekannt gemacht, ich sah die Macht des Thot und war klug in ihren Geheimnissen, so dass ich alle ihre Schwierigkeiten löste und man mich in allen ihren Fällen um Rat fragte" ${ }^{\text {“7 }}$. Dieselbe Inschrift berichtet weiter, daß nach einiger Zeit ihn der König in das Amt eines „Rekrutenschreibers“ (š́ njswt š́ nfrw) mit dem Rang eines "Oberbeamten" beförderte ${ }^{8}$. Man kann aus der Biographie verstehen, dass Amenophis der „Rekrutenschreiber“ der nördlichen Hälfte des Landes war, die allerdings die militärisch wichtigere war. Daraus versteht man, dass Aufgrund seiner Talente und seiner Tatkraft in Verwaltung und Organisation erreichte Amenophis die höchsten Ämter im königlichen Hofe. In seiner Eigenschaft als „Rekrutenschreiber“ bekam er vom König den Auftrag, bei der Leitung von Bauarbeiten mitzuwirken. Deshalb legte er sich auch den Titel „Vorsteher aller Bauarbeiten des Königs“ (jmj-r3 k3t nbt nt njswt). Die Inschriften der Statue des Amenophis, Sohn des Hapu, die er sich als Belohnung im Amuntempel in Karnak aufstellen dürfte, schildert diese Tat in stolzem Ausdruck: „Der König machte mich zum Vorsteher der Arbeiten im Gebel el-Ahmar Bruch ${ }^{9}$, um die Denkmäler seines

$\left.m \check{s}^{\tau}\right)$ zu diesen untergeordneten Stellen. Aus Soldatenschreibern rekrutierten sich die höheren Verwaltungsbeamten des Heeres: der „Vorsteher der Militärschreiber“ (jmj-r3 šs $m \check{s}$ ), der „Rekrutenschreiber“ (š́ njswt š́ $n f r w)$ und der „General“ (jmj-r3 $m \check{s}^{\Upsilon}$ ).

7 W. HELCK, „Der Einfluss der Militärführer in der 18. Dynastie“, in: UGÄ̈ 14, Hildesheim 1964, S. 4.

8 „Rekrutenschreiber“ als Oberbeamter (š́ njswt š́ $n f r w)$ : Dieses Amt scheint erst im Anfang der 18. Dynastie neu geschaffen worden zu sein, denn vorher ist der Titel „Rekrutenschreiber“ nicht überliefert. Sicher gab es einen Rekrutenschreiber zur nördlichen Hälfte Ägyptens und einen zur südlichen Hälfte des Landes. Es erscheinen nie zwei oder mehrere Rekrutenschreiber gleichzeitig. Dieses Amt steht über dem Anfangsamt des „Soldatenschreibers“" (š̌ $m \check{s}$ ).

${ }^{9}$ Ein begehrter Sandsteinbruch, besonders für Sarkophage und kolossale Statuen. Dieser Steinbruch bei Heliopolis war in der 18. Dynastie der bevorzugte Steinbruch der Könige gewesen. Aus seinen harten, grobkörnigen, rötlichen Sandstein, wurden damals gern die königlichen Sarkophage hergestellt. Gerade König Amenophis III. scheint diesen Steinbruch besonders geschätzt zu haben. Die Steine waren vom nördlichen zum südlichen Heliopolis (Theben gemeint) für riesige Monumente und Statuen in Theben stromaufwärts transportiert. M.-G. LEGRAIN, «Au Pylone D'Harmhabi À Karnak (X. Pylone) », ASAE 14, Caire 1914, p. 17-20, pl. 3. 
Vaters Amun in Karnak zu leiten. Ich transportierte seine sehr großen Statuen als Abbilder seiner Majestät in kunstvoller Ausführung, geleitet vom nördlichen zum südlichen Heliopolis; sie ruhen an ihrem Platz im Westen ... Mein Herr ehrte mich aber, indem er meine Statue im Amuntempel aufstellen ließ, denn er weiß, daß ich ihm in Ewigkeit gehöre" ${ }^{\text {"10. }}$. Wahrscheinlich leitete Amenophis auch den Bau des Totentempels, obwohl das nicht ausdrücklich überliefert ist. Es spricht dafür, dass Amenophis, Sohn des Hapu seinen eigenen Totentempel direkt neben den seines Königs in Theben-West zwischen den Bauarbeiterhütten, die für den königlichen Totentempel arbeiteten, anlegen dürfte. Die Inschrift der Statue des Amenophis, Sohn des Hapu, aus dem Amuntempel in Karnak, CG 583, lautet: „Mein Herr machte mich zum Vorsteher aller Bauarbeiten. Da machte ich den Namen des Königs ewig, indem ich nicht nachahmte, was früher getan worden war, sondern ich errichtete ihm einen Berg von Sandstein, der ganze Amuntempel wurde so mit Statuen aus diesem Stein angefüllt, dass er zu einem Sandsteinberg wurde, denn er ist ja Atums- Erbe“"11. Diesen außergewöhnlichen Leistungen des Amenophis, Sohn des Hapu, auf dem Gebiete der Bauleitung stehen nun gleich außerordentliche Ehrungen gegenüber, die ihm sein König gewährte. Es begann mit einer königlichen Erlaubnis ein Grab in der Art der Könige in Theben-West (irgendwo in den Wüstentalern) anzulegen, ferner einen Totentempel am Wüstenrand, was nur ein Privileg der Könige war.

Der König feierte in seinem 30. Regierungsjahr sein erstes Sedfest. $\mathrm{Zu}$ diesem wichtigen Jubiläumsfest war Amenophis,

\footnotetext{
${ }^{10}$ Inschrift der Granit Statue des jungen Amenophis, Sohn des Hapu, gefunden vor dem 10. Pylon des Amuntempel in Karnak, heute im Ägyptischen Museum Kairo: Erdgeschoss, Saal 12, JE 44861; M.-G. LEGRAIN, in: ASAE 14, 1914, p. 17-20, pl. 3; W. HELCK, Urk. IV, Übersetzungen zu den Heften 17-22, Berlin 1961, S. 277, Abschnitt: 1833; W. HELCK, „Der Einfluss der Militärführer in der 18. Dynastie“, UGÄ̈ 14, Hildesheim 1964, S. 5.

${ }^{11}$ L. BORCHARDT, Statuen und Statuetten von Königen und Privatleuten, II, Cat. Gén., Nr. 583; W. HELCK, "Der Einfluß der Militärführer in der 18. Dynastie", in: UGÄ̈ XIV, Hildesheim 1964, S. 6.
} 
Sohn des Hapu, der Sonderbeauftragter des Königs. Aus Anlass dieses Jubiläums leitete Amenophis die Bauarbeit des Amuntempels in Soleb, organisierte die Verwaltung des Tempels und setzte die Priester zum Tempel an ihren Plätzen ein. Die Inschrift der Statue des Amenophis erwähnt, folgendes: „Der König bestimmte mich zum Leiter des Amunfestes bei jedem

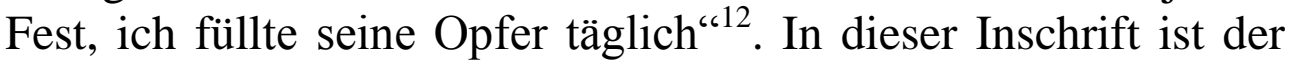
Tempel von Soleb nicht genannt, so zeigt sie jedoch deutlich, daß es sich um die Einrichtung eines Tempels aus Anlaß des 1. Sedfestes handelt. Die hervorhebende Darstellung des Amenophis in Soleb lässt kaum Zweifel zu, daß es der Tempel von Soleb war. Die Ehrung spricht in diesem Fall, daß ihn der König zum „Festleiter des Amun“ einsetzte. Hier erscheint mir ein weiterer Beweis, daß Amenophis, Sohn des Hapu die Stelle eines Kronprinzen gleichkommt, da nur der König dem Amunfest leiten dürfte. Amenophis erhielt also den Auftrag bei den Festen die Rolle des Königs zu übernehmen.

Der Rangtitel $\left(r-p^{\top} t\right)$ erlangte Amenophis als Ehre während des 1. Sedfestes des Königs. Er erhielt die Ehre, die Gestalt des $\left(r-p^{\complement} t\right)$ beim kultischen Spiel des Königs zu verkörpern. Inschrift aus dem Totentempel des Amenophis, Sohn des Hapu, berichtet über diese Stellung, nämlich: „Er war geliebter des Königs, als königliche Schreiber und Gauverwalter eingesetzt, und im Sedfest des Königs eine besondere Rolle teilnahm. Er erhielt Schmuck von Gold und allerlei Edelsteinen; man gab ihn einen Kuhkopfschmuck an seinen Hals aus $\left(\underline{d}^{\top} m\right)$ - Gold und allerlei Steinen. Sitzen auf dem Sitz von Gold gegenüber dem Thron, indem seine Glieder bekleidet sind mit (pk)-Stoff und erstklassigem Linnen .....““13.

Der Rangtitel $\left(r-p^{`} t\right)$ bedeutete auch, dass Amenophis, Sohn des Habu, das Vertreten des Königs bei der Rechtsprechung

\footnotetext{
12 Statue des jungen Amenophis aus dem Amuntempel in Karnak: M.-G. LEGRAIN, „Au Pylone D'Harmhabi À Karnak (X. Pylone) “, ASAE 14, Caire 1914, pl. 3.

${ }^{13}$ Inschrift aus dem Totentempel des Amenophis, Sohn des Hapu: W. HELCK, Urk. IV, Übersetzungen zu den Heften 17-22, Berlin 1961, S. 279, Abschnitt: 1837.
} 
eingesetzt war ${ }^{14}$. Eine Inschrift einer Statue des Amenophis aus dem Chonstempel, lautet: „,..., Mund, der im Palast zufrieden stellt, Vertrauten des Königs beim prächtig Herstellen seiner vielen Denkmäler, Festleiters des Amun, Amenophis, des Gerechtfertigten “ ${ }^{\prime 15}$.

Der Titel $\left(r-p^{`} t\right)$ bringt Amenophis, Sohn des Hapu, zu derselben Stellung eines Kronprinzen. Da der Kronprinz wesentlich das Ziel einer Stellvertretung des Königs beim Heer war, soll unbedingt bedeuten, daß der Titelträger $\left(r-p^{\ulcorner} t\right)$ militärische Handlungen ausüben musste? Es ist bekannt, daß der König der Heeresführer im NR, wie in ältester Zeit war; ihm zunächst steht, wenigstens in der Ramessidenzeit, der Kronprinz als „Erbfürst“ und „Heeresvorsteher“ und „Wedelträger zur Rechten des Königs". Damit, möchte ich andeuten, dass der Titel selbst „Wedelträger zur Rechten des Königs“ kein militärisches Amt war, da Amenophis nie „General“ geworden war, aber der Titel bringt ihn zum engen Königskreis als seine erfahrene, anvertraute und hochbegabte Weise, was auch in militärischen Zügen erfordert war. Das bedeutet, dass die beiden Rangtitel „Wedelträger zur Rechten des Königs" sowie $\left(r-p^{\complement} t\right)$ keine militärischen Verantwortungen voraussetzten, da das Amt eines Generalissimus und Heeresbefehlshaber sowie Soldatenführer vorhanden waren. Hier, muss ich aber erwähnen, dass während meiner Untersuchung, mir erscheint dass die Ämter und Titel von einer Zeit zum anderen ändern. Deswegen, muss ich diese Untersuchung auf die 18. Dynastie beschränken, da sich die Titel mit ihre Bedeutungen und Vorrausetzungen mit der politischen Lage des Landes sowie Sozialaufbau des Staates gerne ändern lassen.

Die Inschriften der vielen Statuen des Amenophis, Sohn des Hapu aus Karnak sowie sein Sarkophag, weisen auf eine Reihe von Amt- und Rangtitel: Er war „Vorsteher der Propheten des

\footnotetext{
${ }^{14}$ W. HELCK, “Rang”, in LÄ V, 1984, S. 146.

15 W. HELCK, Urk. IV., Übersetzungen zu den Heften 17-22, Berlin 1961, S. 278, Abschnitt: 1836.
} 
Horus“, „Herrn des Gaus von Athribis“, und „Siegler des unterägyptischen Königs“"16. Hier erkennt man deutlich einen auftretenden religiösen Titel „Vorsteher der Propheten des Horus", obwohl er eine Reihe von zivilen Verwaltungsämtern ausübte.

Die charakteristischen Bauarbeiten des Königs Amenophis III. von Luxortempel, der 3. Pylon in Karnak und auf dem thebanischen Westufer die gewaltige Anlage seines Totentempels mit den Memnonkolossen und eine Reihe von Kolossalstatuen des Königs sind alle von dem begabten „Bauleiter“ Amenophis, Sohn des Hapu geführt, sowie eine Reihe von Bautätigkeiten in Unterägypten. Er tritt auch sonst als leitender Beamter vor. Als Gunstbeweis des Königs dürfte er seine Statuen im großen Amuntempel von Karnak aufstellen. Außerdem, hatte er das Privileg, einen eigenen Totentempel in der Nähe der königlichen Anlagen in der thebanischen Nekropole. Die 45 x 110 m große Ziegelanlage besaß Merkmale eines Millionenjahrhauses ${ }^{17}$. Hier erkennt man deutlich die hohe Stellung des Amenophis, die einen einfachen hohen Beamten überragt. Er hat die Stellung eines Regenten erreicht, was die Stellung eines Kronprinzen übereinstimmt. Die einfachen hohen Beamten haben keinen Totentempel gehabt. Amenophis arbeitete sein Leben lang im königlichen Hof. Die lange Inschrift, die eine lobende Biographie enthält, verrät, dass Amenophis, Sohn des Hapu, 80 Jahre im königlichen Hofe erreicht hat, und hofft, ein Alter von 110 Jahren zu erlangen ${ }^{18}$.

\footnotetext{
${ }^{16}$ G. LEGRAIN, Statues et Statuettes des Rois et des Particuliers, I, Cat. Gén., Caire 1906, p. 78-80 (Statue Nr. 42127), pl. 76; Statuenfragment des Imn-Htp im British Museum Nr.103: Urk. IV, 1830, 1-5; 1839, 1-12; W. HELCK, Übersetzungen zu den Heften 17-22, Berlin 1961, S. 275, Abschnitt: 1830; Sarg des Imn-htp: Urk. IV, Berlin 1958,1839; Statue aus dem Tempel der Mut zu Karnak: Urk IV, 1831, 12-17.

${ }^{17}$ D. ARNOLD, Lexikon der Ägyptischen Baukunst, Düsseldorf 2000, S. 23.

${ }^{18}$ Erwähnt in der Mitte der 9. vertikalen Zeile auf der Schürze der Statue Nr. 42127; auch Urk. IV, 1828, 7; W. HELCK, Übersetzungen zu den Heften 17-22, Berlin 1961, S. 274, Abschnitt: 1828.
} 
Später, wurde Amenophis vergöttlicht. Die Ptolemäer errichteten für ihn und den ebenfalls vergöttlichten Imhotep eine Kapelle auf der dritten Terrasse des Hatschepsut-Tempels in Deir el-Bahari. Die Inschrift auf der Basis der Statue des 'Imn-htp, Sohn des $H p w^{19}$, aus Karnak, heute im Ägyptischen Museum Kairo, Erdgeschoss, Saal 12, JE 38368, CG 42127, lautet:

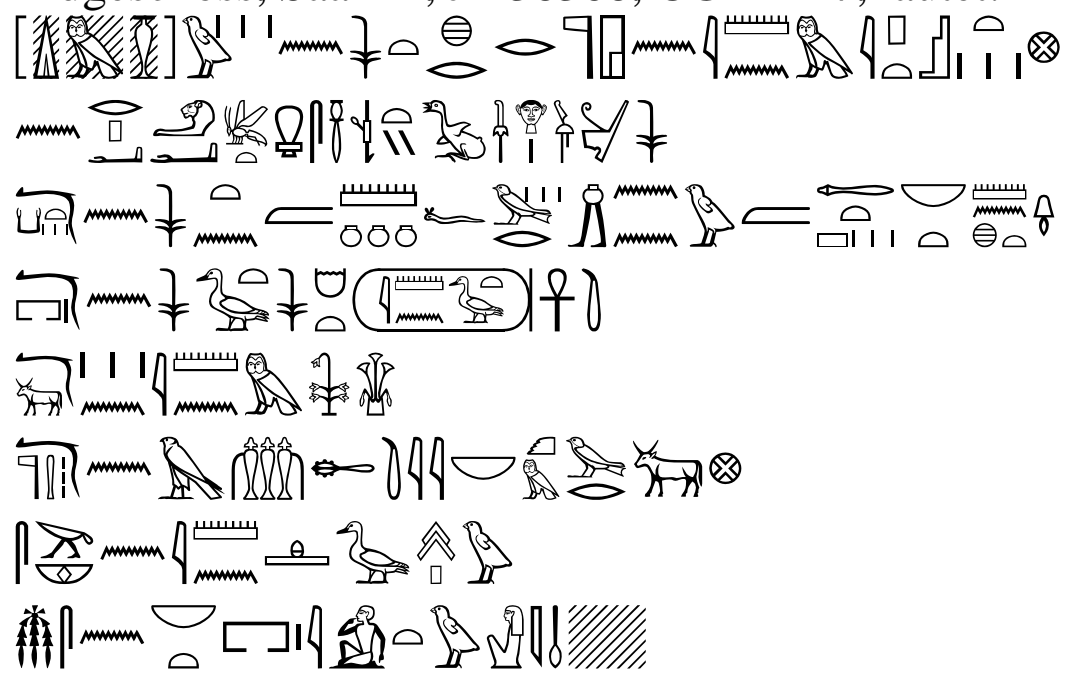

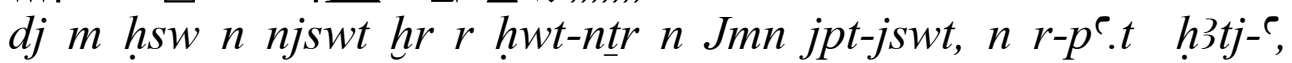

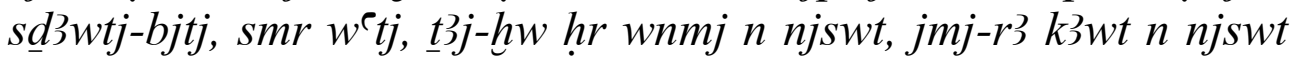
$m m n w=f$ wrw, jnj.nw $m$ '3t nbt mnht, jmj-r了 pr n s3.t njsw.t hm.t njswt (S3.t Jmn), dj ‘nh, jmj-r’ jhw n Jmn $m$ rswt mht, jmj-r3 hmw ntr n Hrw Hntj-htjj, nb Km-writo shb n Jmn, Jmn-ḥtp s3 Hpw, msj $n$ nbt pr Jtw, $m \jmath^{C}-h r w$ [...]

" [Gegeben als königliche Gnaden] beweis ${ }^{21}$ in den Tempel des Amun in Karnak für den $r-p^{\ulcorner} . t$ h3tj- ${ }^{3}$ Gaufürst, Siegler des unterägyptischen Königs ${ }^{22}$, einzigen Freund, Wedelträger zur Rechten des Königs, Vorsteher der Bauarbeiten des Königs an seinen großen Denkmälern, die gebracht wurden aus allerlei trefflichem Stein, Vorsteher des Haushalts der Königstochter und königliche Gemahlin S3.t-Imn, sie lebe, Rindervorsteher des

\footnotetext{
${ }^{19}$ Urk. IV, 1828, 15-19; auch: 1829, 1-3; G. LEGRAIN, Statues, I, Cat. Gén, Nr. 42127, p. 78-80, pl. 76.

${ }^{20}(K m-w r)$ ist Name des Gebiets der Bitterseen.

${ }^{21}$ Gunstbeweis des Königs.

${ }^{22}$ Siegelbewahrer des Königs von Unterägypten ist ein dritt-höchster Hofrangtitel
} 
Amun in Ober- und Unterägypten, Prophetenvorsteher des Horus Hntj-hltj, Herrn von Athribis, Festleiter des Amun. Jmn-ḥtp, Sohn des Hpw, geboren von der Hausherrin Jtw, der Gerechtfertigten“ ${ }^{\text {‘23 }}$.

Anhand dieser Untersuchung erscheint deutlich, dass "Amenophis, Sohn des Hapu“ verschiedene hohe Amtstellen erreicht hat, aufgrund seiner Talente und Begabtheit, die er lebenslang bewiesen hat. Zivile Amtstelle ist anhand des Amtes „Rekrutenschreiber“ nachgewiesen; während seiner Verwaltungsämter durch die vollzogenen Amtstellen „Gaufürst von Athribis“, „Siegler des Königs“ in Unterägypten; „Bauleiter des Königs" bewiesen sind. Die in den Inschriften erwähnten Palast-Hofrang nämlich der „Einzige Freund des Königs“, und „Wedelträger zur Rechten des Königs“ bringen ihn zu einer höheren Sozialstand als der bürokratischen hohen Beamten. Weiterhin hat der fähige Amenophis weitere wirtschaftliche Amtstellen ausgeübt, wie „Rindvorsteher des Amun in Ober- und Unterägypten". Er führte auch als Ehrung den Titel eines Prophetenvorstehers des Stadtgottes von Athribis, des (Hr hntj$\underline{h} t j)$. Er erhielt auch den Rang eines „Festleiters des Amun“, durch den er den König bei Amunfesten vertreten konnte ${ }^{24}$.

In seiner hohen Alter, am Ende der Regierung Amenophis III. trug Amenophis, Sohn des Hapu, das Amt eines Vermögensverwalters der Prinzessin Satamun (jmj-r3 $p r \quad n s 3 t$ njswt wrt S3.t-Jmn). Diese Prinzessin (S3.t-Jmn) scheint am Hofe Amenophis III eine ziemlich große Rolle gespielt zu haben, denn es ist nicht nur auffällig, dass sie einen Vermögensverwalter bekommt, sondern sie wurde von ihrem eigenen Vater (König Amenophis III) geheiratet ${ }^{25}$.

\footnotetext{
${ }^{23}$ Urk. IV, 1828f.; W. HELCK, Übersetzungen zu den Heften 17-22, S. 275, Abschnitt: $1828 \mathrm{f}$.

${ }^{24}$ W. HELCK, ,Amenophis, Sohn des Hapu “, in: LÄ I, 1975, S. 220.

25 W. HELCK, „Der Einfluß der Militärführer in der 18.Dynastie“, in: UGÄ̈ 14, Hildesheim 1964, S. 11.
} 
Amenophis, Sohn des Hapu, erreichte ein Lebensalter von 80 Jahre im königlichen Hofe, was uns bedeutet daß er seine Anständigkeit, Tatkraft und Begabtheit lebenslang bewiesen hat, ferner der vielen Erfahrungen, die er anhand der vielen verschiedenen Amtstellen geleistet hat.

Die Inschriften derselben Statue (CG 42127) erwähnen weitaus persönliche Prinzipien des Amenophis, nämlich er tut die Gerechtigkeit: „Amenophis adressiert Re im Amun-Tempel und sagt: „Du lässt mich unter den Gelobten sein, die die Wahrheit tun. Ich bin ein Wahrhaftiger, nicht bin ich parteiisch, nicht geselle ich mich zu dem Übeltäter. Nicht fluchte ich über seine Bosheit bei einem, der mir bei den Arbeiten unterstellt war. Nicht rief der Mann neben mir, weil ich mich (etwa) nicht darum gekümmert hätte zu hören, was er sagt. Nicht ließ ich zu viel tun, und nicht trat ich dem zu nahe, der für mich arbeitete. Nicht kümmerte ich mich darum, Verleumdung zu hören, um einen anderen bei seinem Vorgesetzten schlecht zu machen. Mein Ruf ist Zeuge für das, was ich getan habe, indem es vor allen Augen ist. Wer mich sah, der wünschte, so wie ich zu sein, weil das, was mir geschah, so groß war. Ein Zeuge für die Wahrheit ist mein Alter: Ich habe 80 Jahre erreicht, indem meine Gunst beim König groß ist, und ich werde auch noch 110 Jahre vollenden“26.

Daraus erfolgt, daß Amenophis leistungsfähig in der praktischen Arbeit war, eine ehrliche Persönlichkeit und vom König vertraut, die ihm zu seiner geachteten Stelle führte. Er war verantwortungsvoll, gerechtvoller Mensch wie er dies in den Inschriften seiner Statue aus Karnak (Kairo Museum CG 42127) behauptet hat: Er habe niemandem übles getan, auch niemals ließ er sich in unwichtige Gerede oder Taten einmischen. Er war ein wahrhaftiger lebenserfahrener Mensch. Sein dienstliches Können einerseits und seine vollständige Persönlichkeit andererseits erlangte ihm den folgenden hohen Ehrentitel zu erreichen:

\footnotetext{
${ }^{26}$ W. HELCK, Urk IV: Übersetzungen zu den Heften 17-22, 1961, S. 274, Abschnitt: $1827-$ 1828.
} 
„Geliebter des Herrn der beiden Länder ${ }^{\text {‘27 }}$, „Einzige Freund des Königs“ und „Wedelträger zur Rechten des Königs“.

Der Rangtitel „Einzige Freund des Königs“ ( $\left.s m r w^{\ulcorner} t j\right)$ wurde im Neuen Reich als Zeichen der Aufnahme unter die Höflinge mit Eintrittserlaubnis in den Palast erwähnt ${ }^{28}$. Der Rangtitel „Wedelträger zur Rechten des Königs“ (țij h̆w hr jmntj wnmj $n$ $n s w t)$ ist wohl nur seit der Hatschepsut belegt. Dieser Rangtitel wurde gern zur Hervorhebung bestimmter Gruppen benutzt ${ }^{29}$. Amenophis, Sohn des Hapu, erhielt mit seiner Pensionierung das Hofamt eines „Wedelträgers zur Rechten des Königs“, wodurch die enge persönliche Verbindung mit dem Königshause ihren Ausdruck fand.

Weitere Belege für den „Rangtitel““ $\left(r-p^{\complement} t\right)$, (t $\underline{3} j$ h hw hr jmntj wnmj $n n s w t$ ), und (š̌ njswt) des Amenophis, Sohn des Hapu, befinden sich auf den Fragmenten seines Sarges in den Museen: Louvre und Brüssel ${ }^{30}$.

Im alten Ägypten kennen wir zwei Baumeister, die fast immer in einem Atemzug mit ihrem Bauwerk und ihrem König genannt werden. Der eine ist Imhotep, der Baumeister der Stufenpyramide des Djoser, welcher später als Weiser und Heilgott verehrt wurde. Der andere, dem eine solche Ehre und Vergöttlichung erfuhr, ist Amenophis, Sohn des Hapu. Die Ptolemäer errichteten für ihn und den ebenfalls vergöttlichten Imhotep eine Kapelle auf der dritten Terrasse des HatschepsutTempels in Deir el-Bahari.

Eine weitere Untersuchung zum Titel „Wedelträger zur Rechten des Königs" geht anhand des hohen Beamten der Kommandant „Nebamun“, Theban Tomb No. 90, in West Theben, in 'Elwet Sheikh 'Abd el-Qurneh. „Nebamun“ war „Kommandant

\footnotetext{
${ }^{27}$ Urk. IV, Übersetzungen, S. 275, Abschnitt: 1830.

${ }^{28}$ W. HELCK, ,Rang “, in: $L \ddot{A}$ V, 1984, S. $146 \mathrm{f}$.

${ }^{29}$ Ibid, S. 147; W. HELCK, „Zur Verwaltung des Mittleren und Neuen Reichs“, Probleme der Ägyptologie, Bd. 3 Leiden-Köln 1958, S. 281ff.

${ }^{30}$ Louvre D 4; Brüssel E 3059; siehe: Urk IV, 1838, 17 und 1839, 1-3.
} 
(Polizeihauptmann) der Fußtruppen ${ }^{\text {(31 }}$ in West-Theben ${ }^{32}$. Eine deutliche Szene in seinem Grab zeigt Nebamun im Moment des Standartenempfangs des neuen Amtes als Kommandant der Truppen in Theben-West ${ }^{33}$. Die Inschriften zu dieser Szene erdeutlicht, dass Nebamun ein ehemaliger Frontkämpfer geworden war und ein hohes Alter im Dienst des Königs erreicht hat $^{34}$. Die neue Amtstellung befördert ihn auch zum „Oberhaupt der Seesoldaten“ auf der königlichen Sonnenbarke „Standartenträger der Schiffs-Mannschaft $h n t . t^{635}$. Bei dieser Beförderung wurde Nebamun ausdrücklich von Steuern für seinen Felder-Besitz befreit ${ }^{36}$. Zu Beginn dieser Ränge war Nebamun ein „Frontoffizier“ aus einer Masse aller Frontoffiziere, der von Steuern befreit worden $\operatorname{war}^{37}$. Durch ihre einzelne Tüchtigkeit hat sie der König unterschiedlich belohnt, einerseits durch Verleihung des „Goldes der Tapferkeit“, auch „Gold der Belobigung" genannt. Eine andere Ehrung bestand darin, einen besonderen Ehrentitel $\mathrm{zu}$ verleihen ${ }^{38}$. Ein weiterer deutlicher Beweis zu der besonderen Erhebung des Nebamuns seitens des Königs.

Die Szenen aus dem Grab des Nebamun ${ }^{39}$ mit deren Inschrift erwähnen diesen Würdetitel. Eine Opferszene zeigt „Nebamun“, der zwei Gänse über zwei flache Handpfannen bringt, und stellt sie als Opfer zum Altar, der vor dem König Tuthmosis IV steht. Nebamun ist von seiner Tochter „Iwjj“ und seiner Gemahlin

\footnotetext{
31 ,the captain of infantry“

${ }^{32}$ N. de G. DAVIES, The Tombs of Two Officials of Tuthmosis IV, Nos. 75 und 90, The Theban Tombs Series, London 1923, p. 23.

${ }^{33}$ Das Emblem der Standarte besteht aus einem Steinbock mit einem Einzelwedel: R.-O. FAULKNER, ,,Egyptian Military Standards “, in: JEA 27, London 1941, pl. VI, fig. 22.

${ }^{34}$ N. de G. DAVIES, Two Officials, pl. 26 and p. $35 f$.

${ }^{35}$ Würdeträger: Oberhaupt der Seesoldaten, Marineoffizier; N. de G. DAVIES, op.cit, pl. 28, und p. 33.

${ }^{36}$ W. HELCK, „Der Einfluß der Militärführer in der 18. Dynastie“, UGÄ̈ 14, Hildesheim 1964, S. 17.

${ }^{37}$ N. de G. DAVIES, Two Officials of Tuthmosis IV., Inscriptions of pl. 26 (west wall-south side 1) and p. 35.

${ }^{38}$ Ibid, p. 40.

${ }^{39}$ Ibid, pl. XX: Hall, east-wall, north side (Scene 1).
} 
, Tjj“ begleitet. „,Tjj“ trägt zwei „,menat-collars“, von denen einer (in ihr linken Hand, mit gebeugtem Arm über ihr Brust) den Namen des regierenden Königs trägt: „,(Mn-hprw-r $\left.{ }^{\top}\right)$, der vollendete Gott, Herr der beiden Länder“. Ein Musikant nämlich ein Lautenspieler schreitet vor der Familie in einer viel kleineren Skala. Normalerweise, in anderen Fällen ist ein Musikant nicht vorhanden, was mir hinweist, dass es um eine besondere obere Sozialfamilie geht. Hinten folgen drei Söhne, die Opfergaben bringen.

Der zugehörende Text in vertikalen Zeilen über den Figuren der Szene, lautet ${ }^{40}$ :
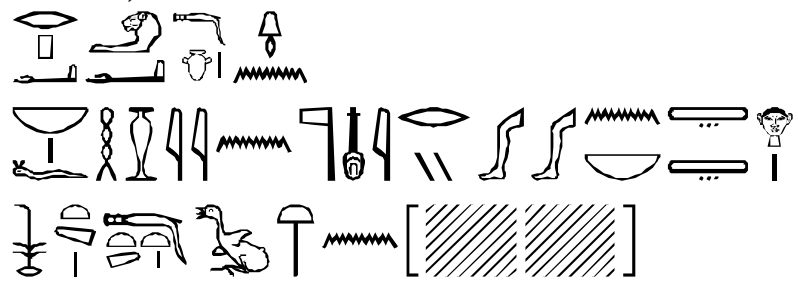

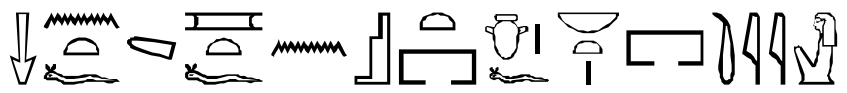

$r-p^{\top} t$ ḩ了tj-? mnh $n$ nb=f hsy $n$ ntr nfr jry rdwy nb t3wy hr rswt mhtt $\underline{t}$ jj-hw $n$ [...]

$s n t=f m r j t=f n$ ist $j b=f n b t p r T j j$

„Opfergaben, aller Arten von allen guten und reinen Dingen... an Amun-re ... , und an Ra-Harakhty, die täglich dem König Gesundheit verleihen, (gebracht) seitens des [Prinzregent (und Erbfürst) der Oberhaupt, anver]raut und tatkräftig für seinem Herr, der Gelobte seitens des guten Gottes, der den Herrn der beiden Ländern im Süden und Norden begleit, der StandarteTräger [des Schiffes Mary-Amun, Nebamun]. Seine geliebte Gemahlin, gethront in seinem Herz, die Herrin des Hauses ${ }^{41}$ Ty. “ Aus dieser Inschrift erfolgt, dass „Nebamun“ militärische Ämter trug, nämlich „Oberhaut der Polizeitruppen in West-Theben“ und „Standarteträger der Schiffs-Mannschaft auf der königlichen Sonnenbarke“.

\footnotetext{
${ }^{40}$ Ibid, pl. XX, Text: vertical-columns 5-9; and p. 24.

${ }^{41}$ Herrin des Hauses ist ein Ehrentitel
} 
Eine weitere Szene lässt uns den hohen Beamten „Nebamun“ genauer betrachten ${ }^{42}$ : Nebamun, seine Gemahlin (Ty) und ihre vier Töchter sind sitzend dargestellt. Gnade und Würde reflektiert sich anhand der Stellung der Figuren einerseits und durch die vielfältigen Einzelheiten der Szene andererseits. Die jüngere Tochter ,,Weret" sitzt neben ihrer Mutter, während die ältere „Segrettawi“" vor ihr Vater „Nebamun“ sitzt. Diese Tochter ist in einer selbständigen Skala mit einer Krone über ihr Kopf wiedergegeben. Die Inschrift erdeutlicht ihre besondere geehrte Stellung seitens des Königs. Die Inschrift beschreibt sie als „Ornament des Königs, den er liebt, begehrte des guten Gottes, Segrettawi, ..." Sie wird seitens einer ihrer jüngeren Geschwister bedient ${ }^{43}$. Reste dieser Szene erhält Spuren für eine Opferspeise, die der geehrten Tochter „Segrettawi“ seitens ihrer Familie vorgelegt wird. Die „Banquet" Szene ist von Musikanten begleitet, nämlich ein Lautenspieler und eine tanzende Lautenspielerin. Die gehörende Inschrift dieser Szene steht in vertikale Zeilen über der ganzen Szene, die folgendes lautet:
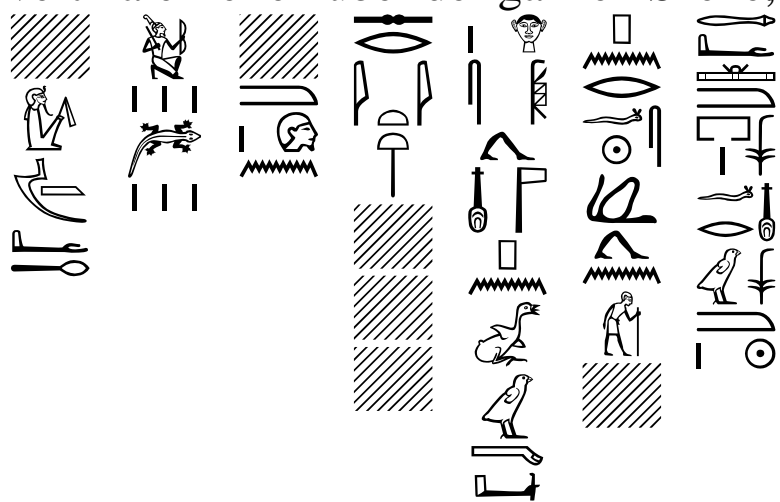

3 $m$ nsw pr nfr nsw m hrw pn $r$ sf ph $n$ ỉw [...]

hr šmsw ntr nfr pn $\underline{t 3 w}$ sryt $[\ldots \ldots \ldots]$

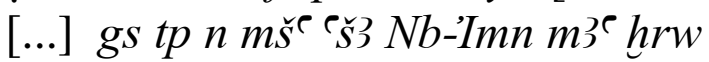

\footnotetext{
${ }^{42}$ N. de G. DAVIES, op.cit., pl. XXI: Hall, east-wall, north side (Scene 2).

${ }^{43}$ PM I, p. 184 (no. 6); DAVIES, Two Officials, p. $28 \mathrm{f}$.
} 
„Groß im Palast, der heute fröhlicher ist als gestern, und erreichte das hohe Alter ${ }^{44}$ im Gefolge diesen guten Gottes, der Standartenträger des [Mary-Amun], [wirksame Dienst] an der Spitze von vielen Soldaten, Nebamun, der Gerechtfertigte."

Daraus erfolgt, daß „Nebamun“ ebenfalls wie Amenophis, Sohn des Hapu, leistungsfähig war und erreichte ein hohes Alter in der Gunst des Königs. Seine Gemalin (Tjj) trug den Ehrentitel (Nb.t$p r$, während die Mutter des Amenophis, Sohn des Hapu nämlich (Jtw) ebenfalls den Ehrentitel (Nb.t-pr) trug.

Beide „Nebamun“ und Amenophis, Sohn des Hapu, sind in den Inschriften als ( $\left.r-p^{`} t h 3 t j-{ }^{\top}\right)$ beschrieben. Das heißt, daß beide an der Spitze der Hierarchie standen und gleicht in der Stellung einen Prinzregent. Die beiden gehören zu den Höflingen des Königs, was den bürokratischen hohen Beamten überschreitet.

Eine einzige Szene behält noch die vollständige Inschrift, die das Amt des Nebamuns erdeutlicht, nämlich „Standartenträger des Schiffes Mary-Amun"، ${ }^{\text {45 }}$, während alle andere Szenen mit ihren Inschriften den Namen des königlichen Sonnenschiffs (MaryAmun $)^{46}$ aufgrund der Beschädigungen verlieren. In dieser Szene überreicht der letzte Kommandant des königlichen Sonnenschiffes (Mary-Amun) dem Nebamun die Standarte des Amtes, deren Inschrift lautet:

\footnotetext{
${ }^{44}$ DAVIES, op.cit, pl. XXVI erdeutlicht ebenfalls das hohe Alter des „Nebamun“, den er in der Gunst des Königs erreicht hat.

${ }^{45}$ N. de G. DAVIES, op.cit., pl. XXVI.

${ }^{46}$ Mrj Jmn: Geliebt von Amun.
} 


I’j srjjt Nb-Jmn dpw njswt Mrj Jmn
"Nebamun, der Standartenträger des Königsschiffs (Mrj-
Hier muß ich bekannt geben, daß (t’3j srjjt) scharf zu trennen
ist von einem ,Standartenträger“ und „Wedelträger zur
Rechten des Königs“.
(t3j srjjt) weist auf ein militärisches Amt nämlich Frontoffizier
„Leiter des Königsschiffes“ (Oberhaupt der Seesoldaten), was
eine besondere Standarte als Emblem des Amtes trägt.

Weitere Szene zeigt das Amt und die Stellung des Nebamuns deutlich dar. „Nebamun“ steht vor dem Thron-Kiosk des Königs, hält in der linken Hand eine Standarte, die aus dem normalen langen Stab besteht und endet oben an ihrer Spitze mit einer eigenartigen Emblem nämlich ein Schiff mit einem herausragendem halbkreisförmigen Fächer an einer Schiffsmitte $^{47}$. Es handelt sich deutlich um sein Amt als „Standartenträger des königlichen Sonnen-Schiffes, MaryAmen“. Mit derselben Hand hält „Nebamun“ eine Schnur, an der syrische Gefangene gefesselt sind. Mit der rechten Hand erreicht „Nebamun“ dem König einen Papyrusstrauß. R.O. Faulkner bestätigt, dass die Benennung (srjt) auf militärische und Marine Standarten beschränkt sind. Beide Standarten ( $h w$ ) und (srjt) erscheinen gleich aus, sie bestehen nämlich aus einem halbkreisförmigen Fächer an dem oberen Ende einem langen Stab. Der Unterschied steht deutlich bei dem Determinativ der Benennung von (srjt), nämlich Holz oder Metall, während das Wort $(h w)$ aus einer Straußenfeder besteht, um kühles Wind dem

\footnotetext{
${ }^{47}$ N. de G. DAVIES, op.cit., pl. XXVIII: Hall, west-wall, north-side (Scene 1); PM I, 1994, p. 185 (no. 9); R.-O. R.-O. FAULKNER, “Egyptian Military Standards”, in: JEA 27, pl. IV, fig. 8 .
} 
König zu zufächeln. Die Standarte (srjt) erscheint deswegen mit massiver roter Befärbung, da es aus festem Holz besteht ${ }^{48}$.

Man muß deutlich unterscheiden zwischen Figuren, die wirklich in den Szenen „Fächer" tragen und eine begabte Persönlichkeit mit dem Ehrentitel „Wedelträger zur Rechten des Königs““49. Die Personen, die hinter dem König folgen und tragen Fächerstandarte waren niedere Bedienstete. Sie werden in der 18. Dynastie als ( $h b s w$ bht $n h m=f)$ „Fächerträger seiner Majestät“ bezeichnet. Für diese Tätigkeit nahm man gern die besten der Gefangenen Neger oder Syrer, während der Rangtitel „Wedelträger zur Rechten des Königs“ eine vom König verliehene Ehre zu einer besonderen Tüchtigkeit bedeutete. Die beiden letzten untersuchten Hofränge „Amenophis, Sohn des Hapu“ und „Nebamun“ sind niemals mit einem „Wedel“ in den Szenen dargestellt, obwohl beide den Ehrentitel „Wedelträger zur Rechten des Königs" tragen.

Die altägyptische Benennung zu unserem untersuchten Rangtitel „Wedelträger" ( $h w)$ wurde im Neuen Reich mit einem EinzelnenStraußenfeder mit kurzem Griff widergegeben. Dieser EinzelStraußenfeder war ein wichtiger religiöses Symbol für "Sonnenschatten“ $\left(\check{s} w t-R^{\varsigma} w\right)^{50}$. Diese Benennung „Sonnenschatten“ bedeutet nicht die Abschirmung der Sonnenstrahl bzw. „Schatten“, sondern „Reflexion“ und „Widerspiegelung“ der Sonnenstrahlen im Festhof ${ }^{51}$ der Gedächtnistempel des Neuen Reiches. Der „Sonnenhof" ist nämlich die Kultstätte des Atum-Re in seinem Aspekt als Schöpfer- und Urgott, in dem sich die göttliche Eigenschaft des „Strahlens“ manifestiert ${ }^{52}$. Im „Festhof“, indem ein Altar

\footnotetext{
${ }^{48}$ R.-O. FAULKNER, “Egyptian Military Standards”, in: JEA 27, London 1941, p.13.

49 Ibid, pl. XXVII: Soldaten schreiten mit halbkreisförmigen Fächern zum königlichen Thron-Kiosk hin.

${ }^{50}$ H.-G. FISCHER, ,,Fächer und Wedel “, in: LÄ II, 1977, S. 81f., Fig. E.

${ }^{51}$ Festhof bedeutet der zweite offene Hof im Gedächtnistempel des Neuen Reiches: siehe El-Badrawy, S., Die Tempelhöfe im Neuen Reich, Diss, Hamburg 2005, S. $370 f$.

${ }^{52}$ R. STADELMANN, „Šwt-R`w“ als Kultstätte des Sonnengottes im Neuen Reich “, MDAIK 25, S. 160f., Wiesbaden 1973.
} 
befindlich ist, opfert der König dem Sonnengott „Atum-Re“, da der König die Kosmosordnung, dass früher seitens des Schöpfergottes Atum-Re geschaffen war, weiterführt. Hier fungiert der König deutlich als Stellvertreter des Urgottes AtumRe, der den Lebenszyklus weiterführt. Der König führt die Kosmosordnung anhand seiner Verpflichtungen und Verantwortungen, die nur durch begabte und leistungsfähige Persönlichkeiten gelungen kann. Diese fähigen Persönlichkeiten waren die hohen Beamten, die wegen ihrer besonderen Begabtheit den Rangtitel „Wedelträger zur Rechten des Königs“ verliehen worden. Sie übertragen eine königliche Teilmacht, da sie an der Führung der Kosmosordnung teilnehmen. Rangtitel, in diesem Fall bedeutet begabte und vertraute Persönlichkeiten, die mit dem König zusammen eine kräftige und feste Gruppe bilden, um das Land bestens weiterzuführen und den ganzen Kosmosordnung anständig im Zyklus zu behalten. Das war die oberste Spitze des bürokratischen Aufbaus, Kopf des Landes und Schutz zur ganzen weltlichen Ordnung. „Regent" ist nach dieser Vorstellung eine vielmehr glänzende und erhobene Stellung als man dachte, die bis zur Vergöttlichung reichen kann, wie z.B. der "Weise“ Amenophis Sohn des Hapu, der in Deir El-Bahari vergöttlicht worden war. Es sind Personen, die die Fähigkeit haben, einen deutlichen Fortschritt in der „Kultur“ bzw. „Leben“ bilden. Die „Regierung“ war für die alten Ägypter eine große Verantwortung, die nur besondere Persönlichkeiten erreichen dürften.

Eine dritte Untersuchung zum Rangtitel „Wedelträger zur Rechten des Königs" läuft anhand einer Untersuchung zum Rangtitelträger der „Militärbeamter“ Haremheb, der später am Ende der 18. Dynastie, nach der Regierungszeit des Tutanchamun den Thron besteigt. „Haremheb“ beginnt seine Karriere als „Militärbeamter“ nämlich Offizier während der 
Regierungszeit des Königs Thutmosis $\mathrm{IV}^{53}$, was Haremhab in seinem Grab in Theben TT 78 erwähnt. Die Blickpunktszenen im Grab zeigen seine Berufsausübungen des Haremheb, nämlich Militärszenen, Verwaltung und Tribute der Fremdvölker ${ }^{54}$. Der Titel (š́ njswt š̌ nfrw) weist auf dem Beginn seiner Karriere während der Regierungszeit des Thutmosis IV als „Rekrutenschreiber“55. Es ist wichtig zu erwähnen, daß dieselbe Inschrift Haremheb als „Vertrauten seines Herrn“ und „Begleiter des Herrn der beiden Länder" nennt, nämlich: jn mh-jb mnh $n$ $n b . f$ jrj $r d w y$ n $n b$ t3wy, bedeutet ,Seitens des vorzüglichen Vertrauten seines Herrn, des Begleiters des Herrn der beiden Länder " ${ }^{\text {"56 }}$. Daraus erfolgt, dass der Ehrentitel „Wedelträger zur Rechten des Königs“" nicht nur die Leistungsfähigkeit verlangt aber auch die anständige, taugliche und vertrauungsvolle Persönlichkeit.

Haremheb war unter Echnaton (Amenophis IV.) Befehlshaber

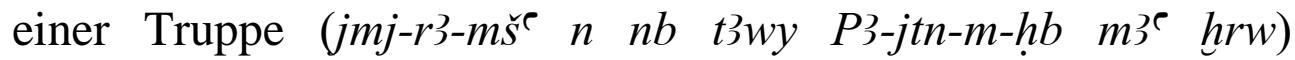
befördert. Das unvollendete Grab des Haremheb in Tell elAmarna (Nr. 24) erwähnt ihm weitere Amttitel: „königliche Schreiber" (š̌ njswt) und „Leiter der Bauarbeiten in „Akhetaten“

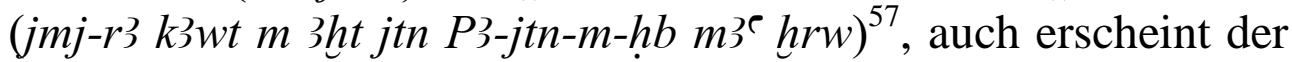
Titel „Oberdomänenverwalter des Königs“ (jmj-r3- pr $n b t 3 w y)^{58}$. Haremheb wurde unter Tutanchamun zum Oberbefehlshaber $\left(j m j-r 3-m s^{\ulcorner}-w r\right)$ und zum Regenten $\left(r-p^{c} t j d n w n n j s w t\right)^{59}$ mit

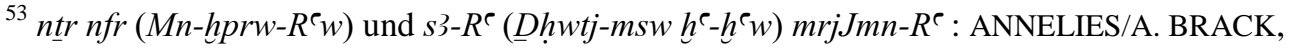
Das Grab des Haremheb, Theben Nr. 78, AV 35, Mainz 1980, S. 32 Abb. 14, senkrechte Zeile c.

${ }^{54}$ ANNELIES/BRACK, op.cit, S. 18, Königsszenen 1.4.1.1.

${ }^{55}$ Ibid, S. 23, Abb.3 (Text 1), 6te-7te vertikale Zeile (stark beschädigt); S. 32, Abb. 15 (Text 14), erste vertikale Zeile.

${ }^{56}$ Ibid, S. 23, Abb.3 (Text 1), vertikale Zeilen 4-5; S. 41, Abb. 23 (Text 22), 2-te vertikale Zeile.

${ }^{57}$ G. DARESSY, Tombeaux et Stèles - Limites de Hagi Qandil - in : RecTrav 15, Paris 1893, p. $45,2^{\text {te }}-4^{\text {te }}$ vertikale Zeile.

${ }^{58}$ N. de G. DAVIES, The Rock Tombs of El Amarna, V, ASE 17, London 1908, pl. 13, $3^{\text {rd }}$ vertical column.

${ }^{59}$ (jdnw $\left.n n s w t\right)$ ) bedeutet Stellvertreter des Königs: Wb I, 1926, S. 154, 4 - 6.
} 
außergewöhnlichen Vollmachten berufen. Er stand auch über die Wesire, die die Zivilregierung repräsentierten ${ }^{60}$. Der Titel $\left(r-p^{\top} t\right)$ erhebt den bürokratischen hohen Beamten zum Kreis der Höflinge und sogar eine Stufe höher zum Regenten. Hier, in diesem Fall erkennt man die volle Bedeutung eines Titels $\left(r-p^{\ulcorner} t\right)$. Es bedeutet das „Vertreten des Königs bei der Rechtsprechung“, und „Vertreten des Königs in den Feldzügen“, da er ursprünglich ein militärisches Amt trug nämlich „Generalissimus des Heeres“ während der Regierungszeit des Tutanchamun und zuletzt hat er den Thron bestiegen trotz seiner einfachen Abstammung. Der Titel $\left(r-p^{\complement} t\right)$ enthält auch die Bedeutung eines "Stellvertretener Leiter", der über die Wesire, die die Zivilregierung repräsentierten, stand. Hier steigt ein hoher Beamter anhand seiner besonderen Begabtheit und Leistungsfähigkeit zu der Stellung eines königlichen Prinzen. Das bekannteste seiner Regierung ist die Erstellung seines Edikts ${ }^{61}$ zur staatlichen Neuordnung. Die Eltern des Haremhebs sind nicht in seiner Biographie erwähnt, da sie nicht einmal mit Namen genannt sind, so kann man feststellen, daß sie nicht der Beamtenschaft angehörten. Seine Gemahlin war (Nódmt-Mwt) eine Tochter des Eje.

Der Rangtitel $\left(r-p^{\top} t\right)$ und ( $t 3 j$ hyw $n$ wnmj $n$ njswt) sind belegt durch die Schreiberfiguren des Haremhebs (Taf. 2), und in den Szenen seines Grabes in Saqqara, dessen Reliefs in den Museen der ganzen Welt ${ }^{62}$ verstreut sind. Die Titel des Haremheb erscheinen auf einem Türfragment im Louvre C 69/70, lauten ${ }^{63}$ :

\footnotetext{
${ }^{60}$ J. v. BECKERATH, ,Haremheb “, in: LÄ II, 1977, S. $962 \mathrm{f}$.

${ }^{61}$ Erlaß, große Stele mit seinem Edikt am 10.Pylon in Karnak.

${ }^{62}$ Leiden, Wien, Berlin, Louvre, Brooklyn, Bologna, und Kairo.

${ }^{63}$ Urk IV, 2088, Titel auf Türfragmenten (Louvre C 69/70), Zeile 13-19: aus seinem memphitischen Grab; R. HARI, Horemheb et la Reine Moutnedjmet, Genève 1964, pl. I, II a.
} 


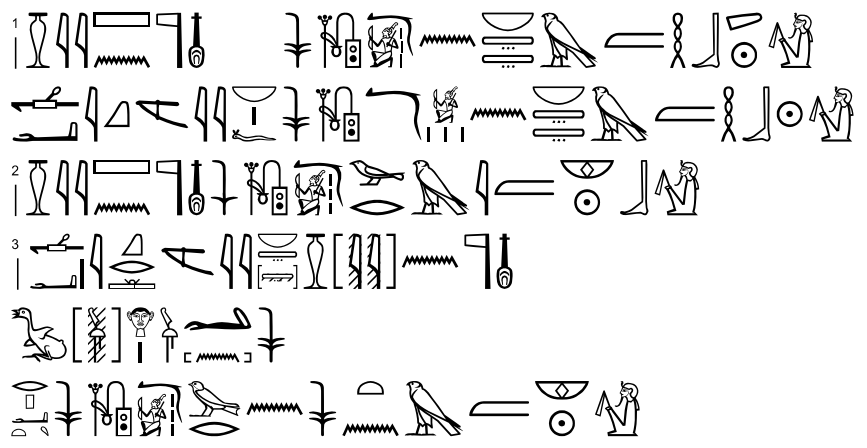

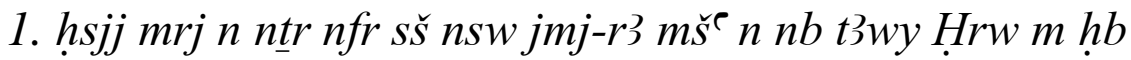
$w^{\complement} j k r m r j n b=f$ š̌ $n s w$ jmj-r’ $m \check{s}^{\complement} n n b$ t3wy Hrw $m$ hb

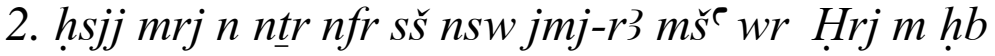

3. $w^{\complement}$ jkr mrj nb t3wy hasjj $n$ ntr $n f r$

ţ̧y hww hr wnmj n njswt

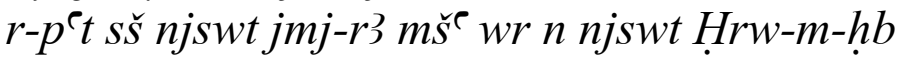

1. „Gelobter und Geliebter des guten Gottes, königliche Schreiber, Oberbefehlshaber des Heeres des Herrn ${ }^{64}$ der beiden Länder Haremheb. Einzig Tüchtiger, Geliebter seines Herrn der beiden Länder, Haremheb".

2. „Gelobter und Geliebter des guten Gottes, königliche Schreiber, Generalissimus Haremheb".

3. „Einzig Tüchtiger, Geliebter des Herrn der beiden Länder, Gelobter des guten Gottes, Wedelträger zur Rechten des Königs, $\left(r-p^{\top} t\right)$, königliche Schreiber, Generalissimus des Königs, Haremheb"65.

Die Berufung Haremhebs zum „Oberdomänenverwalter“ (jmj-r3 $p r w r)$ und zum „Oberbefehlshaber des Heeres“ (jmj-r’ $m \check{s}^{\ulcorner} w r$ ) hatte Haremheb eine Macht in die Hand gegeben, wie sie innerhalb der 18. Dynastie noch kein Mann außerhalb der königlichen Familie gehabt hatte. Er war zum tatsächlichen Stellvertreter des Königs geworden mit dem Titel $\left(r-p^{\top} t\right)$, die den Regenten bezeichnet. Haremheb führte die Regierung für den

\footnotetext{
${ }^{64}$ König Tutanchamun

${ }^{65}$ W. HELCK, Urk. IV, Übersetzungen zu den Heften 17-22, Berlin 1961, S. 393.
} 
unmündigen König Tutanchamun, ohne selbst aus dem Königshaus zu stammen. Eine wichtige Rolle des Haremhebs als Regenten wird anhand eines Inschrifts bewiesen, nämlich: „r-p`t, h3ty-?3, Generalissimus, Zunge des Königs, die im ganzen Land zufrieden stellt, Hr-m-hb. Das heißt, das Vertreten des Königs bei der Rechtsprechung “66.

Eine Türlaibung aus dem Grab des Haremheb in Saqqara zeigt den Grabinhaber in betende Haltung, mit dem Wedel an seinem Rücken befestigt (Taf. 2). Der Obere Teil der Paneele nennen eine Reihe von Amts-, Rang- und Ehrentitel des Haremheb: 1. (r-

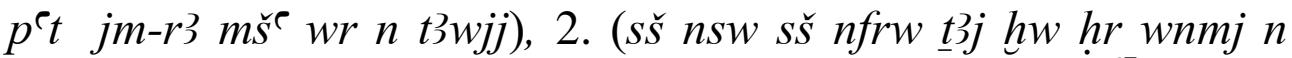
njswt) .... (jmj m jb n Hrw meh.f ...) 3. (...jmj-r3 k3t ....) ${ }^{67}$, 6. (..r-

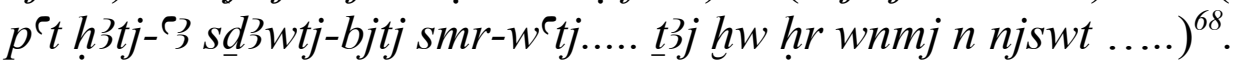

Haremheb diente eine lange Zeit im königlichen Hofe, beginnend mit der Regierungszeit des Echnatons, folgt Tutanchamun und Eje, dann Haremheb selbst zum Thron. Er zeigte besondere Ehre an Wissenschaft und Literatur, deswegen auch die besondere Ehre des Schreibergotts „Thot“. Haremheb, als König stellte sich gerne in Schreiberform dar. Seine Statue in Schreibergestalt im Ptahtempel in Saqqara beweist seine Bescheidenheit (Taf. 3). Seine Klugheit und Urteilsfähigkeit lassen ihn die richtige Entscheidung $\mathrm{zu}$ nehmen, indem er eine Ruhezeit mit dem hethitischen König entschließen hat, um die erschütterte innere Ordnung im Land wie auch das verlorene militärische Ansehen Ägyptens in Vorderasien wiederherzustellen. Seine Gnade und Barmherzigkeit erkennt man, indem er die Syrier und Kanaaniten, die durch die Angriffe der Hethiter verhungert sind, ein friedliches Leben in Ägypten zugesichert hat. Haremheb leistete eine Reihe von Denkmälern sowie ein Projekt von Wiederaufbau der zerstörten Bauten während der Amarnazeit.

\footnotetext{
${ }^{66}$ Ibid, S. 393, Abschnitt: 2089 (Fragment aus dem memphitischen Grab des Haremheb, Kairo).

${ }^{67}$ I.-E.S. EDWARDS, Hieroglyphic Texts from Egyptian Stelae, etc., British Museum, part 8, BM 1939, pl. 27, no. 550, cols. 1-3.

${ }^{68}$ Ibid, pl. 27, no. 552, col.: 6 .
} 
Eje bestieg den Thron nach dem Tod des jungen Königs Tutenchamun, obwohl er nicht blutsmäßig mit der königlichen Familie verbunden war. Da er über seine Familie vollkommen schweigt und seine Eltern nicht einmal mit Namen nennt, so darf man sicher erwähnen, dass Eje nicht aus einer Familie stammte, die der Beamtenschaft angehörte. Die Hinweise zu Eje sind gering, um deutlich seine Lebenskarriere betrachten zu können. Sein Name erschien während der Regierungszeit des Königs Amenophis III. Eine Inschrift auf einem Kästchen in Berlin Museum Nr. 17555 nannte ihn „Frontoffizier“69. In El-Amarna während der Regierungszeit des Echnaton tritt Eje im königlichen Hof als „Befehlshaber der Streitwagentruppe“. Seine Gattin Teje war die ,große Amme“ der Königin Nofretete, was ihm gelang in das Amt eines Kavalleriegenerals eingesetzt zu werden. Eje trug noch ein hervorgehobener Titel nämlich „Gottesvater" (jtj-ntr), was eine verwandtschaftliche Verbindung zum König hinweisen lässt ${ }^{70}$. Über Ejes Tätigkeit und Einfluss unter Echnaton sagen weder er selbst noch irgendwelche Dokumente etwas aus. Nach dem Tode Echnatons verschwanden alle Großen. Eje war der einzige, der unter Tutanchamun wieder in seiner alten Stellung auftaucht. Man kann gut verstehen, dass Staat und Dynastie auf den guten Willen der Militärführer angewiesen war. Das Grab des Eje in Memphis erwähnt die folgenden Titel:

$(\underline{t} 3 j-h w w \text { hr wnmj } n j s w t)^{71}=$ „Wedelträger zur Rechten des Königs“; $\quad(j t j-n t r r)^{72}=$ „Gottesvater"; $(\text { sš-njswt jmj } m r j=f)^{73}=$

\footnotetext{
${ }^{69}$ H.-W. HELCK, Der Einfluß der Militärführer in der 18.Dynastie, UGÄ̈ 14, Hildesheim 1964, S. 73; Die Frontoffiziere wurden nach Beendigung ihres Dienstes an der Front nicht nur in Posten der königlichen Begleitung, sondern auch in zivile Verwaltungsstellen am Hofe und in der Vermögensverwaltung des Königs versetzt.

${ }^{70}$ J. v. BECHERATH, ,,Eje “, in: $L \ddot{A}$ I, 1975, S. 1211.

${ }^{71}$ N. de G. DAVIES, The Rock Tombs of El-Amarna, VI, ASE 18, London 1908, pl. XXXI, cols. 4-5 (vertical lines, right and left).

${ }^{72}$, Ibid, pl. XXXI, col. 6 (vertical lines).

${ }^{73}$ Ibid, pl. XXXI, col. 5 (vertical lines).
} 
„königliche Schreiber, beliebt von ihm“ und (jmj-r3 ssmw) $=$ „Befehlshaber der Pferdegespann"“74.

Während der Regierungszeit des jungen Tutenchamuns berief Eje die Stellung des Wesirs $(\underline{t} 3 t j)$, um Staatsgeschäfte zu leiten und die alte Amuns-Religion zu restaurieren. Die Inschriften beweisen dass Eje der Oberhaupt der königlichen Gefolge und im Hofe des Königs gealtert war, nämlich: $(\ldots j w=j m-h 3 t s m s w=f$, smsw njswt tpj t3wy šmsw $n b h m=f)^{75}$, bedeutet ,... ich bin an der Spitze seiner Höflinge, die Ältesten des Königs (die Höflinge), die über den beiden Ländern sind, und alle Geleit seiner Majestät." Diese Inschrift erdeutlicht genau die Stellung des Eje im königlichen Palast, nämlich stand er an der Spitze der Höflinge, was uns andeutet, dass er ebenfalls im königlichen Hof gealtert war. Nach dem Tod des Tutenchamuns bestieg Eje selbst den Thron, den er etwa 4 Jahre innehatte.

In diesem Fall kann man merken, dass Eje den Thron - trotz er den Titel des Regenten ( $\left.r-p^{\ulcorner} t h 3 t j-{ }^{-3}\right)$ nicht trug - bestieg. Eje gelang ihm den Thron zu besteigen, da er an der Spitze der Höflinge stand und das Amt eines Wesirs geführt hat.

Mehrere Inschriften aus dem Grab des Eje in El-Amarna erwähnen diesen Ehrentitel ${ }^{76}$ und seine Amtstitel:

„Der Wedelträger zur Rechten des Königs, der Befehlshaber aller Streitwagentruppen des Herrn der beiden Länder, geliebter königlicher Sekretär, der Gottesvater, ein Tüchtiger, ein Erfolgreicher, der dem „,Ka" seiner Majestät nachfolgt. Ich bin einer, der seine Vollkommenheit schauen durfte, wenn er in seinem Palast erschien, denn ich stand an der Spitze der Beamten und Höflinge, der erste Mann des Königs in seinem ganzen Gefolge. Ich bin der Erste der Großen und an der Spitze des Volkes. Ich bezeuge euch die Beweise der Gunst des Königs““77.

\footnotetext{
${ }^{74}$ G. DARESSY, «Tombeaux et Stèles-Limites de Hagi-Qndil », in : Rec.Trav. XV, Paris 1893 , p. $45 \mathrm{f}$.

${ }^{75}$ Ibid, p. 47, col.10; N. de G. DAVIES, El-Amarna VI, pl. XXXII, col. 4 ; pl. XXV, col. 12.

${ }^{76}$ Urk. IV, Heft 22, 1997- 2002, Nr. 756.

${ }^{77}$ H.-A. SCHLÖGL, Echnaton - Tutanchamun, 4. Aufl., Wiesbaden 1993, S. 124f.
} 
In der Amarnazeit, im Grab des Meryra II (Grab Nr. 2) erscheint Echnaton und Nofretete im Erscheinungsfenster bei der Verleihung des Ehrengoldes an leistungsfähigen Beamten ${ }^{78}$. Dabei erscheinen Personen aus dem Hofstaat mit Wedel. Diese Art von Darstellungen gehört nicht zu dieser Untersuchung, da der Artikel über den Ehrentitel „Wedelträger zur Rechten des Königs" spricht und nicht um Personen, die in Begleitung des Königs einen Wedel tragen. Hier muss man einen deutlichen Unterschied sehen.

\section{Ergebnisse:}

1. Der Titel „Wedelträger zur Rechten des Königs“" ist eine Ehrenbezeichnung, die der König für besondere Leistungen von hohen Beamten verlieh. Diese Beamten könnten Verwaltungsbeamten wie Wesire, Schatzhausmeister und Oberdomänenverwalter sein, sowohl militärische Oberbefehlshaber und Königssohn von Kusch.

2. Die Verleihung dieses Titels verlangt außer den besonderen Leistungen des Amtes auch die taugliche Persönlichkeit. Wissen, Kenntnisse und Leistungsfähigkeit waren wichtige Vorraussetzungen zu diesem Ehrentitel „Wedelträger zur Rechten des Königs". Sie begannen ihren Lebenskarriere als „Rekrutenschreiber“" und lassen sich gerne in Schreiberform darstellen oder in betende Haltung.

3. Die Träger diesen Ehrentitels waren Vertrauungsvolle Persönlichkeiten, haben Lebenslang im königlichen Hofe gedient, haben einen hohen Alter erreicht, und bildeten dabei persönliche Beziehung zum König.

4. Die Träger dieses Ehrentitels waren von der BürokratieApparat zu einer besonderen Hofklasse hervorgehoben. Sie überschreiten sogar die Hofklasse und bilden ihre oberen Spitze. Sie standen als Leiter der königlichen Höflinge (smsw), was die Ältesten des Palastes bedeutet hat ${ }^{79}$.

\footnotetext{
${ }^{78}$ N. de G. DAVIES, El-Amarna, II, pl. 33.

${ }^{79}$ smsw = Ältester, der Älteste, die Ältesten, Kronprinz: Wb IV, 1971, S. 142, 10, 16.
} 
5. „Wedelträger zur Rechten des Königs“ waren diejenigen, die die Beamten auf ihre Plätze stellten.

6. Die Eltern eines Titelträgers „Wedelträger zur Rechten des Königs" müssen nicht zu der geachteten Bürokratie gehören, da Amenophis, Sohn des Hapu sein Vater und Eje seine Eltern in ihren Biographien nicht erwähnen.

7. Der Titelträger begann meistens seine Lebenskarriere als königliche „Rekrutenschreiber“ (š̌ njswt š́ nfrw), danach folgten mehrere geachtete Verantwortungen, die ihm der König aufgrund seiner Leistungsfähigkeit und Zuverlässigkeit beriefen hat. Diese waren vor allem "Schatzhausvorsteher“ (jmj-r3 $p r \quad h \underline{d}$ ), „Obervermögensverwalter des Königs“ (jmj-r3 pr wr), „Vezire“ und „Vorsteher aller Bauarbeiten des Königs“ (jm-r3 k3t šs $n j s w t)$, „Oberbefehlshaber der Truppen“ (jmj-r3 mš $w r)$, auch „Siegelträger des Königs“ (s $\underline{d} 3 w t j$ bjtj). Manchmal auch „Prinzenerzieher" und „Gottesväter“"80.

8. Seit Thutmosis IV. erhält jeder Vizekönig von Kush diesen Titel und wird damit eine besondere Hofklasse eingestuft.

9. Er spielte eine besondere Rolle während des Sed-festes des Königs.

10. Es handelt sich nicht um ein militärisches Amt, sondern ein Ehrentitel aufgrund besondere Leistungen und Zuverlässigkeit.

11. In den meisten Fällen trugen die Personen mit dem Titel „Wedelträger zur Rechten des Königs“ einen weiteren Titel nämlich ( $\left.r-p^{\top} t h 3 t j-{ }^{\top}\right)$, was nur den Prinzregenten betrifft. Daraus erfolgt, dass die meisten Titelträger „Wedelträger zur Rechten des Königs" die Spitze der Bürokratie und sogar die Spitze der Höflinge überschreiten und stehen Parallel zu den Prinzregenten. Er trug eine enge persönliche Beziehung zum König.

12. Der „Wedel“" war ein einzelner Straußenfeder mit kurzem Griff, oder „Fächer“ mit mehreren Straußenfedern an einem langen Griff. Dieser Wedel gehört im Neuen Reich zur

\footnotetext{
${ }^{80}$ Eine vollständige Übersicht zu den Amtstitel und Ehrentitel: H.-W. HELCK, Verwaltung, Probleme der Ägyptologie, 3, S. $441 \mathrm{ff}$.
} 
Begleitung des Königs bei seinem Erscheinen in der Öffentlichkeit. Diese Darstellungen brauchen eine weitere Untersuchung, da man deutlich unterscheiden muss zwischen Träger des „Ehrentitels“, die an der Spitze der Höflinge standen und die Königseskorte, die als Diener oder Soldaten wirklich in den Darstellungen einen „Wedel“ oder „Fächer“ in Begleitung des Königs getragen haben.

13. Ein „Wedel“ oder „Fächer“ mit Straußfedern symbolisiert die Bedeutung des „Sonnen-Schattens“ nämlich $\left(\check{s} w t-r^{\complement} w\right)$, was eine wichtige Eigenschaft des Königs wiedergibt als Nachfolger des Schöpfergottes „Atum “. Der Träger des Ehrentitels „Wedelträger zur Rechten des Königs" stand als Emblemträger des ( $\left.\check{s} w t-r^{\ulcorner} w\right)$, was ihm die Führung des Staates genauso wie der Prinzregent legitim stellt, trotz er nicht aus der königlichen Familie stammt, wie als Beispiel „Eje“.

14. Seit der Amarnazeit gehört der Zeremonialwedel fest zur Ausstattung der Prinzessinnen, Hofdamen und Hofstaates. Es handelt sich hier um die Symbolik des „Wedels“ zum Sonnengott „Atum-Re“ und zum König als Erbe des Gottes.

15. Dieser Ehrentitel beginnt während der Regierungszeit der Königin Hatschepsut zu erscheinen und erreicht den Höhepunkt im Laufe der 18. Dynastie. In der 19. und 20. Dynastie verliert der Ehrentitel teilweise seine Vorraussetzungen.

16. Der Träger des Ehrentitels „Wedelträger zur Rechten des Königs" hält in Königsdarstellungen keinen Wedel in seiner Hand. Diejenigen, die in den Darstellungen dem König mit einem „Wedel“ begleitet haben, waren Soldaten oder einfache Diener (Taf. 4).

17. Haremheb erschien in einigen Darstellungen aus seinem Grab in Memphis mit dem Wedel an seinem Rücken befestigt (Taf. 2). Eje erschien manchmal in seinem Grab in El-Amarna während seines Gebets mit dem Wedel in seiner linken Hand zusammen mit einem Krummstab und Beil ${ }^{81}$. Merkbar ist, dass Eje seine

${ }^{81}$ N. de G. DAVIES, El-Amarna, VI, pls. XXXIX, XXXI. 
Insignien während seiner Gebete hält, aber keinmal vor dem König.

18. Der Rangtitel „Einzige Freund des Königs“" (smr $w^{\complement} t j$ ) wurde im Neuen Reich als Zeichen der Aufnahme unter die Höflinge mit Eintrittserlaubnis in den Palast erwähnt. Dieser Rangtitel war einer der Eigenschaften eines ,Wedelträgers zur Rechten des Königs".

19. Die Träger dieser Ehrentitel stammen ursprünglich aus unterschiedlichen Sozialklassen.

20. Da meistens der Ehrentitel ,Wedelträger zur Rechten des Königs" mit dem Ehrentitel $\left(r-p^{c} t\right)$ verbunden war, so hat der Träger dieser beiden Titel die Gunst des Königs-Vertretens bei der Rechtsprechung, Zunge des Königs, der im ganzen Land zufrieden stellt.

21. ( $t_{3 j} j$ srjjt) ist scharf zu trennen von einem „Standartenträger“ und „Wedelträger zur Rechten des Königs“. Es handelt sich hier um ein bestimmtes Emblem eines militärischen Amts, nämlich ein Frontoffizier als Oberhaupt der Seesoldaten „Leiter des Königsschiffes". 


\section{Bibliographie:}

ANNELIES/BRACK 1980

ANNELIES/A. BRACK, Das Grab des Haremhab, Theben Nr. 78, AV 35, Mainz 1980.

ARNOLD 2000

D. ARNOLD, Lexikon der Ägyptischen Baukunst, Düsseldorf 2000.

BECKERATH 1975

J. v. BECKERATH, ,Eje“, in : LÄ I, Wiesbaden 1975.

BECKERATH 1977

J. v. BECKERATH, ,Haremheb“, in: LÄ II, Wiesbaden 1977.

BORCHARDT 1911-36

L. BORCHARDT, Statuen und Statuetten von Königen und Privatleuten im Museum von Kairo, in: Catalogue Général, II, Berlin 1911-36.

DARESSY 1893

G. DARESSY, Tombeaux et Stèles- Limites de Hagi Qandil- in: RecTrav 15, Paris 1893.

DAVIES 1904

N.de G. DAVIES, The Rock Tombs of El-Amarna, II, ASE 14, London 1904.

DAVIES 1908

N.de G. DAVIES, The Rock Tombs of El-Amarna, V, ASE 17, London 1908.

N.de G. DAVIES, The Rock Tombs of El-Amarna, VI, ASE 18, London 1908.

DAVIES 1923

N. de G. DAVIES, The Tombs of Two Officials of Tuthmosis IV., Nos. 75 and 90,

The Theban Tombs Series, London 1923.

EDWARDS 1939

I.-E.S. EDWARDS, Hieroglyphic Texts from Egyptian Stelae, etc., part VIII, British Museum 1939.

ERMAN/GRAPOW 1957-1971

A. ERMAN/H. GRAPOW, Wörterbuch der ägyptischen Sprache, 6. Bde, BerlinLeipzig 1957- 1971.

FAULKNER 1941

R.-O. FAULKNER, ,Egyptian Military Standards “, in: JEA 27, London 1941.

FISCHER 1977

H.-G. FISCHER, ,,Fächer und Wedel“, in: LÄ II, Wiesbaden 1977.

HARI 1964

R. HARI, Horemheb et la Reine Moutnedjmet, Genève 1964.

HELCK 1958

H.-W. HELCK, Urkunden der 18. Dynastie, IV, Hefte 20-22, Berlin 1958.

HELCK 1958

H.-W. HELCK, „Zur Verwaltung des Mittleren und Neuen Reichs “, Probleme der Ägyptologie, Bd. III, Leiden-Köln 1958.

HELCK 1961

H.-W. HELCK, Urkunden der 18. Dynastie, IV: Übersetzungen zu den Heften 17-

22, Berlin 1961. 
HELCK 1964

H.-W. HELCK, „,Der Einfluss der Militärführer in der 18. Ägyptischen Dynastie“, in: UGA $\ddot{A}$ XIV, Hildesheim 1964.

HELCK 1975

H.-W. HELCK, „Amenophis, Sohn des Hapu“, in: LÄ I, Wiesbaden 1975.

HELCK 1984

H.-W. HELCK, ,Rang “, in: $L \ddot{A} \mathrm{~V}$, Wiesbaden 1984.

LEGRAIN 1906

G. LEGRAIN, «Statues et Statuettes des Rois et des Particuliers », I, Catalogue Général (42001-42138), Caire 1906.

LEGRAIN 1914

M.-G. LEGRAIN, «Au Pylone D’Harmhabi 'À Karnak (X. Pylone) », ASAE, XIV, Caire 1914.

PORTER/MOSS 1994

B. PORTER/M. MOSS, Topographical Bibliography of Ancient Egyptian Hieroglyphic Texts, Reliefs, and Paintings, vol. I: (The Theban Necropolis, part 1. Private Tombs), Oxford 1994.

SALEH/SOUROUZIAN 1986

M. SALEH/H. SOUROUZIAN, Offizieller Katalog: Die Hauptwerke im Ägyptischen Museum Kairo, Mainz 1986.

SCHLÖGL 1993

H.-A. SCHLÖGL, Echnaton - Tutanchamun, 4. Aufl., Wiesbaden 1993.

STADELMANN 1973

R. STADELMANN, “(Šwt-R`w) als Kultstätte des Sonnengottes im Neuen Reich”, MDAIK 25, Wiesbaden 1973.

WINLOCK 1937

H.-E. WINLOCK, Egyptian Statues and Statuettes: The Metropolitan Museum of Art, New York 1937. 


\section{Liste der abgekürzt zitierten Zeitschriften und Reihen}

ASAE Annales du Service des Antiquités de l'Égypte, Caire

ASE

Archaeological Survey of Egypt

AV

Archäologische Veröffentlichungen

$\mathrm{BM}$

British Museum

MMA The Metropolitan Museum of Art, New York

CG/Cat.Gèn. Catalogue Général des Antiquités Égyptienne du Musée du Caire, Caire

JEA

Journal of Egyptian Archaeology, London

$\mathrm{LÄ}$

Lexikon der Ägyptologie, Wiesbaden

MDAIK Mitteilungen des Deutschen Archäologischen Instituts, Abteilung Kairo

UGA $\ddot{A}$ Untersuchungen zur Geschichte und Altertumskunde Ägyptens, Hildesheim

Urk Urkunden des ägyptischen Altertums, Berlin

$\mathrm{Wb}$ Wörterbuch der ägyptischen Sprache, 6 Bde, Berlin-Leipzig, 1957. 


\section{Bildverzeichnis:}

Taf. 1: Der gealterte Amenophis, Sohn des Hapu, Grauer Granit, Neues Reich, 18. Dynastie, gefunden von Legrain nördlich des 7. Pylons in Karnak, Zeit Amenophis III, 1403-1365 v. Chr. Seine Hände liegen in der Haltung eines Betenden ausgestreckt auf den Oberschenkeln.

Das Ägyptische Museum, Kairo, Erdgeschoss, Saal 12, CG 42127. Grauer Granit, gefunden nördlich des 7. Pylons in Karnak. Zeit Amenophis III, 1403-1365 v. Chr.

M. SALEH/H. SOUROUZIAN, Offizieller Katalog: Die Hauptweke im Ägyptischen Museum Kairo, Mainz 1986, Nr. 149.

G. LEGRAIN, „Statues et Statuettes des Rois et des Particuliers", Catalogue Général, I. Caire 1906, pl. 76.

Taf. 2: Türlaibung aus Kalkstein, Grab des Haremheb in Saqqara: Darstellung in Tiefrelief stellt Haremheb in betende Haltung dar mit dem „Wedel“ an seinem Rücken befestigt, was auf seinem Ehrentitel „Wedelträger zur Rechten des Königs“ hinweist. Regierungszeit Tutenchamun.

I.-E.S. EDWARDS, Hieroglyphic Texts from Egyptian Stelae, etc., British Museum, Part VIII, BM 1939, pl. 27, no. 552.

Taf. 3: Der Generalissimus Haremheb in Schreiberform, Grauer Granit, aus dem Ptah-Tempel in Memphis, 1358-1350 v. Chr. Die Darstellung eines Generalissimus in der begehrten Schreiberform weist auf die wichtige Vorraussetzung des Ehrentitels „Wedelträger zur Rechten des Königs“ nämlich „Wissen“ und „Kenntnisse“.

H.-E. WINLOCK, Egyptian Statues and Statuettes, in: The Metropolitan Museum of Art, New York 1937, no. 19.

Taf. 4: Im Kiosk thront der König Thutmosis IV. Er sitzt auf einem mit reicher Einlegearbeit dekorierten Thronstuhl mit hoher Rückenlehne und mit Löwenfüßen. Vor dem König stehen zwei Wedelträger auf dem Thronsockel, sie sind teilweise von der Kiosksäule verdeckt, tragen in ihrer Rechten je einen hohen Wedel und bringen mit der Linken das Königsszepter ( $h k 3)$. Vor dem Thron steht der Grabinhaber Haremheb auf einer weißen Estrade mit schräger Rampe. Er überreicht dem König einen riesigen Papyrusstabstrauß, nämlich das „Amunbouquet“.

ANNELIES/A. BRACK, Das Grab des Haremheb, Theben Nr. 78, AV 35, Mainz 1980, Taf. 86 und 6d. 


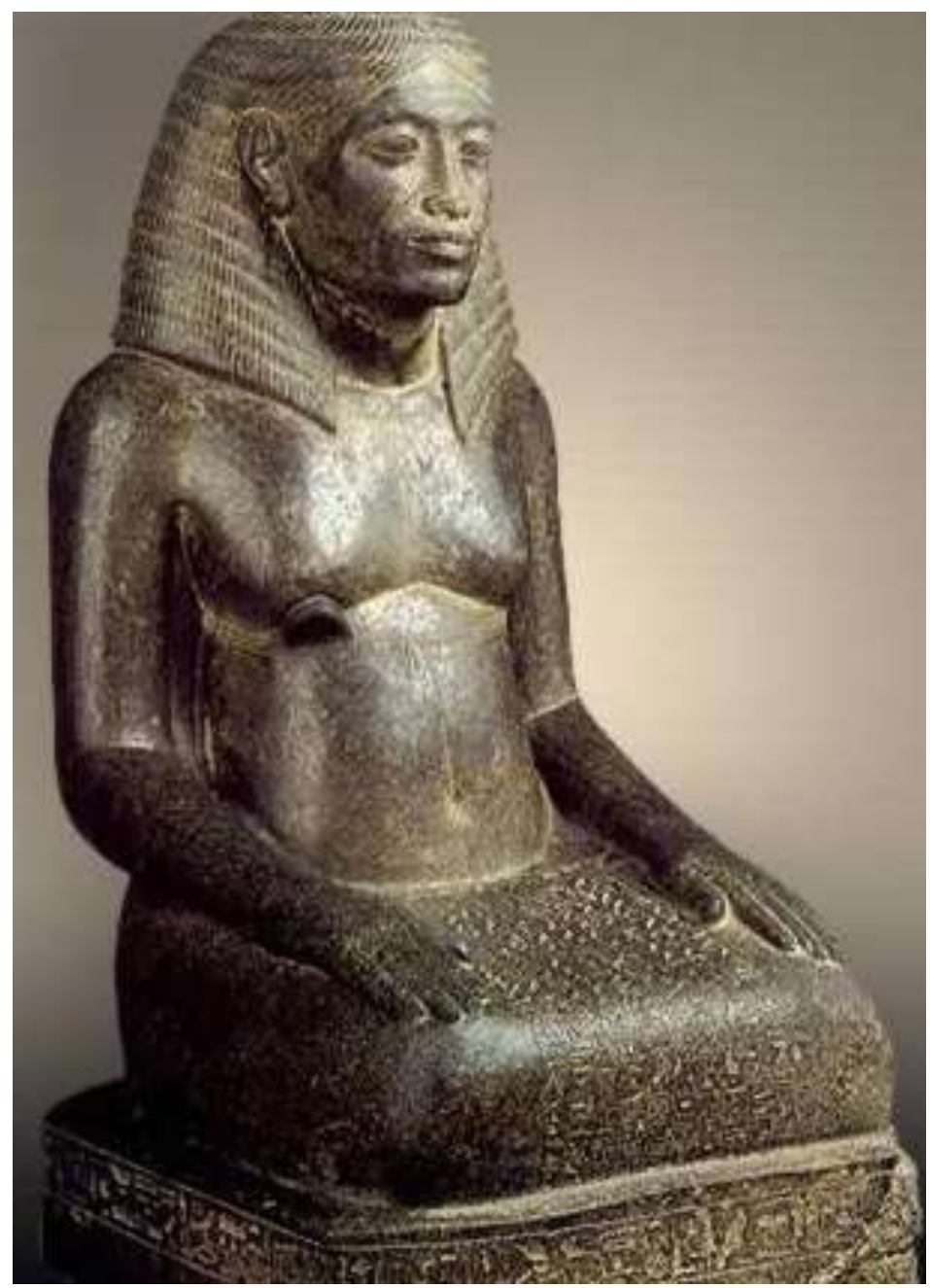

Taf.1: Der gealterte Amenophis, Sohn des Hapu in betende Haltung. Ägyptisches Museum, Kairo, Erdgeschoss, Saal 12, CG 42127 
JOURNAL OF The General Union OF Arab Archaeologists (1)

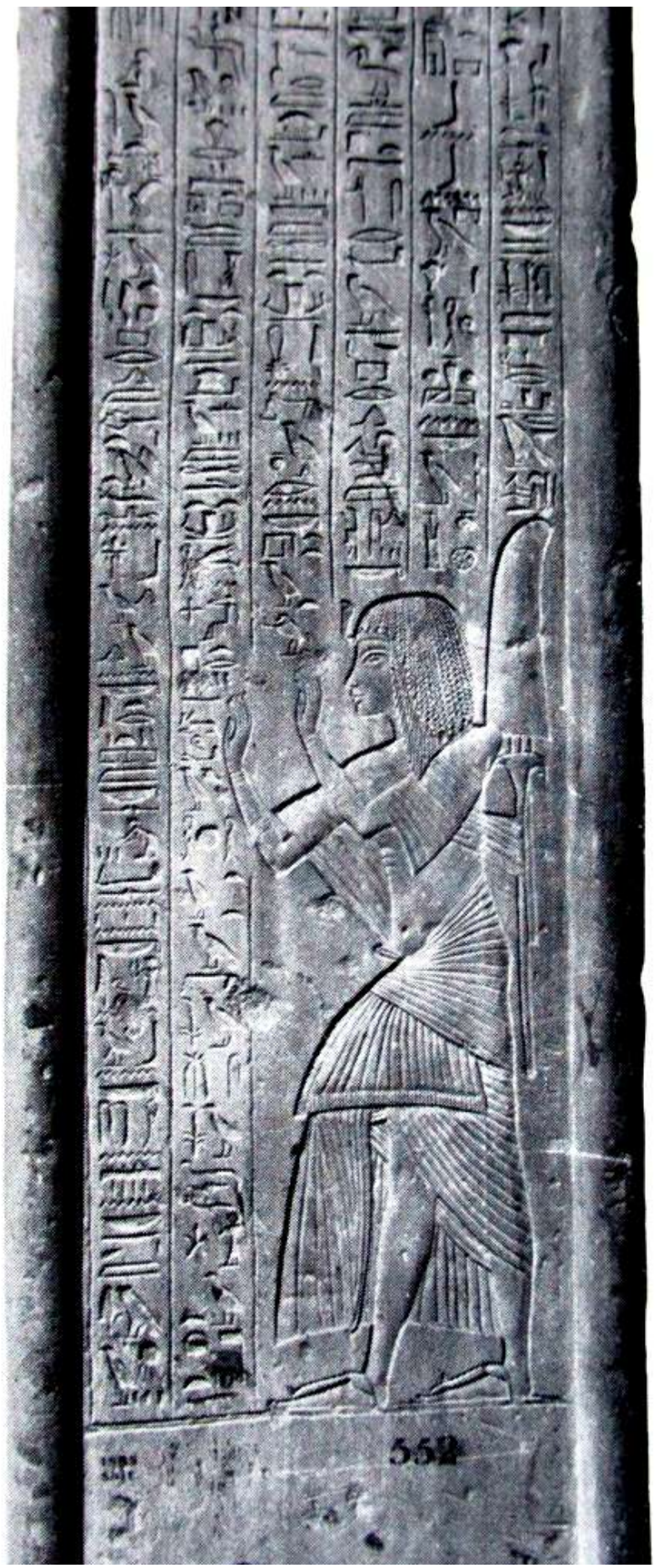

Taf. 2: Türlaibung aus dem Grab des Haremheb in Saqqara. I.-E.S. EDWARDS, Hieroglyphic Texts from Egyptian Stelae, \& etc., in: BM, part 8, BM 1939, pl. 27, no. 552 


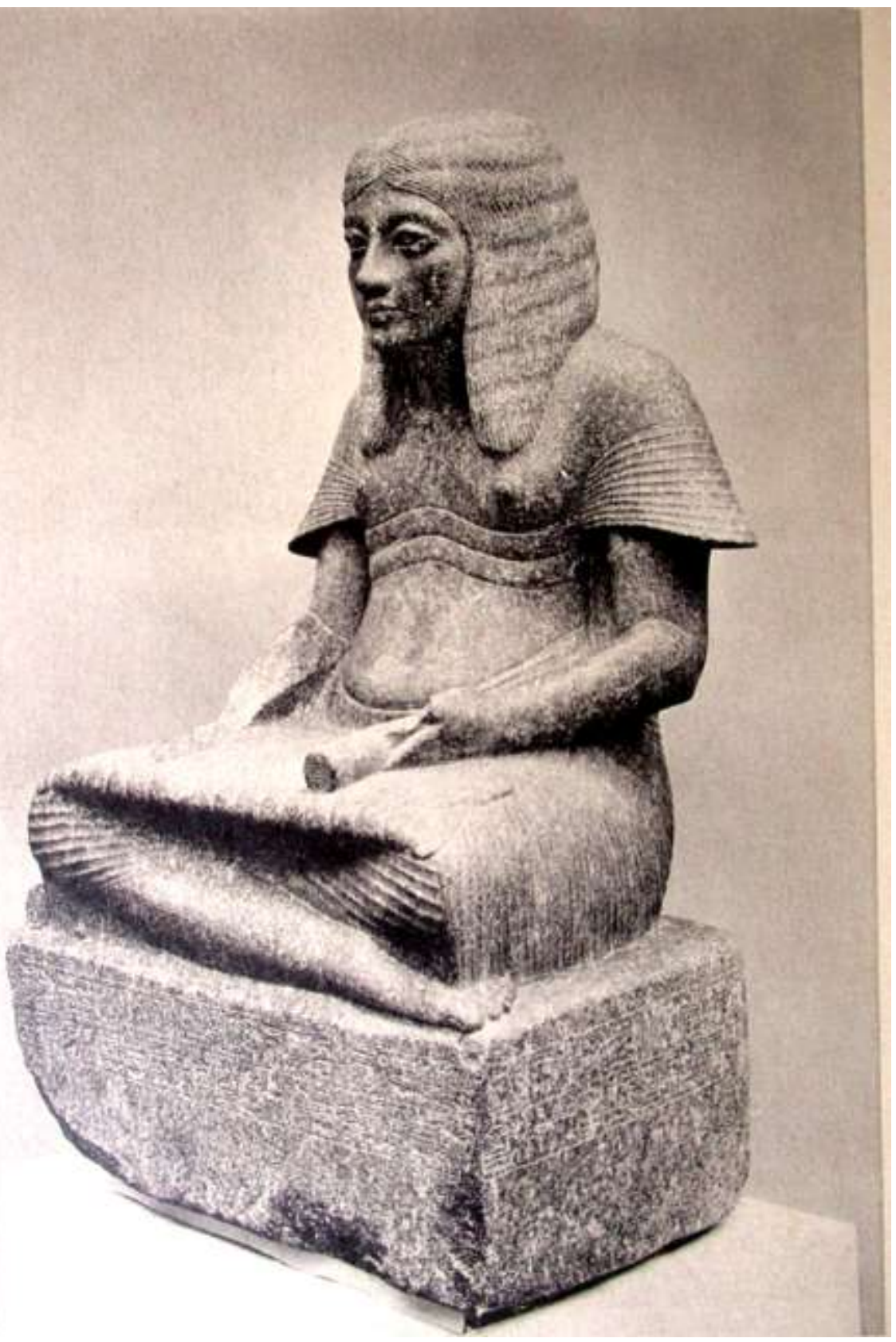

Taf. 3: Der Generalissimus Haremheb in Schreiberform; Grauer Granit; aus dem Ptah-Tempel in Memphis, 1358-1350 v. Chr. H.-E. WINLOCK, Egyptian Statues and Statuettes, MMA, New York 1937, no. 19 


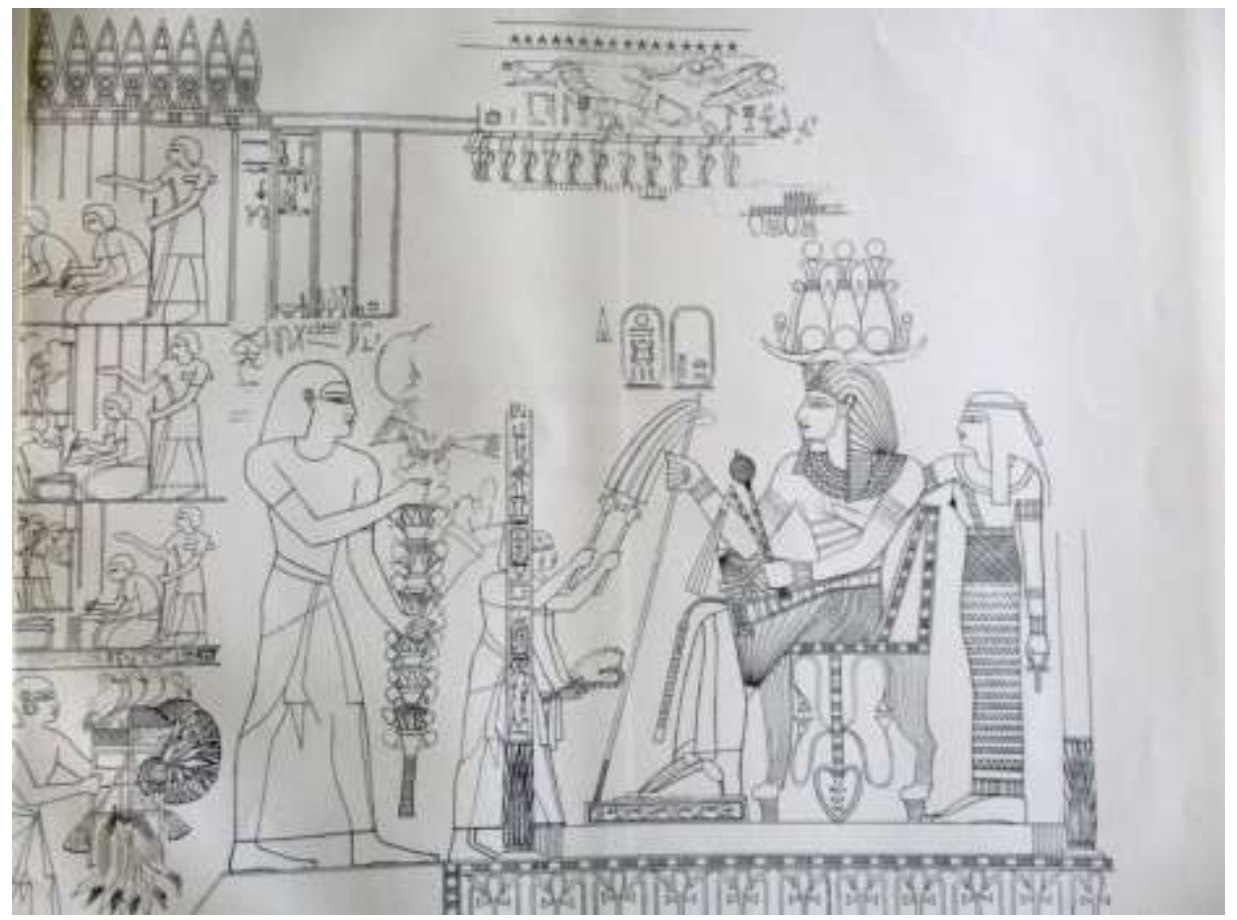

Taf. 4: Das Grab des Haremheb; Theben Nr. 78; Sheikh Abd El-Qurna; Querhalle südliche West-Wand. ANNELIES/A. BRACK, AV 35, Taf. 86 


\section{حامل الريشة الملكية على يمين الملك \\ في الأسرة الثامنة عشى علئ}

\section{د.سحر سمير البلراوين}

يقوم هذا البحث على إجر اء در اسة تحليلية للقب حامل الريشة الملكية على يمين

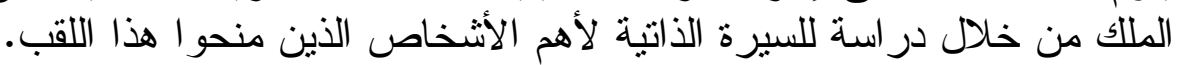
وقد قامت الدراسة على الأشخاص الآنية:

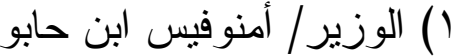

$$
\begin{aligned}
& \text { r) بئيس الثرطة الثرة نب آمون }
\end{aligned}
$$

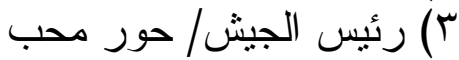

$$
\begin{aligned}
& \text { ع) رئيس المركبات/ آي }
\end{aligned}
$$

تقوم هذه الاراسة على آلى ستة محاور:

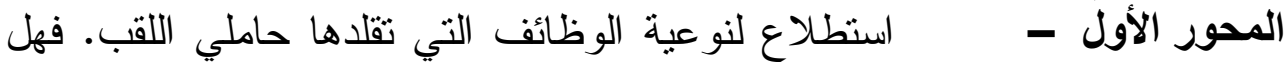
كان اللقب ينحصر في وظائف عسكرية أو دينية أو إدارية؟

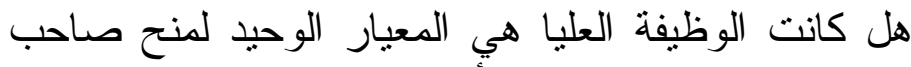

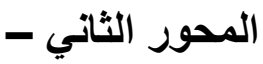

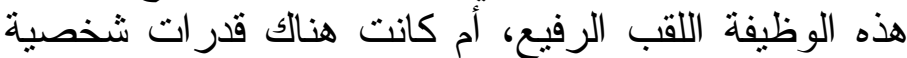

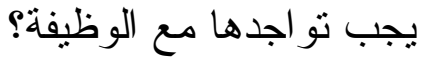

هل كان صاحب اللقب ينتمي إلى أسرة تلى تعمل في النظام

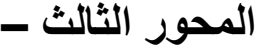

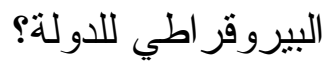

للإجابة على هذا التساؤل استوجب البحث إلى التطرق إلى وظائف أهلية حامل

التعرف على الطبقة الاجتماعية لصاحب اللقب من خلال

تتبع مظاهر الرقي في مناظر مقابر أصحاب اللقب.

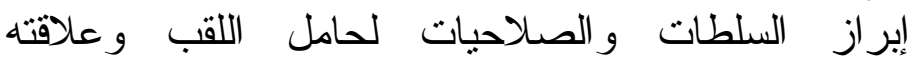

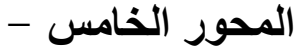

$$
\text { المباشرة بالملك. }
$$

اختلفت معايير هذا اللقب خلا الأسرة التاسعة عشر و العشرون، لذلالك ينحصر

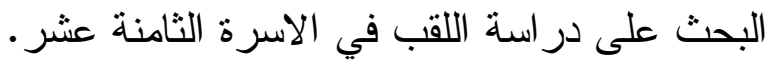
المحور السادس - اظلهار المعنى الدينى و السياسى للريشة الملكية و حامل 